San Jose State University

SJSU ScholarWorks

Master's Theses

Master's Theses and Graduate Research

2003

\title{
Evaluating monitoring practices of community-based ecotourism projects
}

Suzanne M. Behrenfeld

San Jose State University

Follow this and additional works at: https://scholarworks.sjsu.edu/etd_theses

\section{Recommended Citation}

Behrenfeld, Suzanne M., "Evaluating monitoring practices of community-based ecotourism projects" (2003). Master's Theses. 2393.

DOI: https://doi.org/10.31979/etd.psbm-r5pv

https://scholarworks.sjsu.edu/etd_theses/2393

This Thesis is brought to you for free and open access by the Master's Theses and Graduate Research at SJSU ScholarWorks. It has been accepted for inclusion in Master's Theses by an authorized administrator of SJSU ScholarWorks. For more information, please contact scholarworks@sjsu.edu. 


\title{
EVALUATING MONITORING PRACTICES OF COMMUNITY-BASED ECOTOURISM PROJECTS
}

\author{
A Thesis \\ Presented to \\ The Faculty of the Department of Environmental Studies \\ San Jose State University \\ In Partial Fulfillment \\ of the Requirements for the Degree \\ Masters of Science
}

By

Suzanne M. Behrenfeld

San Jose, California

May 2003 
UMI Number: 1415705

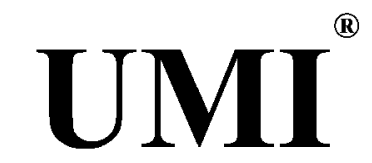

UMI Microform 1415705

Copyright 2003 by ProQuest Information and Learning Company.

All rights reserved. This microform edition is protected against unauthorized copying under Title 17, United States Code.

ProQuest Information and Learning Company 300 North Zeeb Road

P.O. Box 1346

Ann Arbor, MI 48106-1346 
(C) 2003

Suzanne Marie Behrenfeld ALL RIGHTS RESERVED 
APPROVED FOR THE DEPARTMENT OF ENVIRONMENTAL STUDIES

Lester Renting

Dune Tate:

Wad Brewer -Lame

Wendy Brewer-Lama, Ecotourism Specialist

APPROVED FOR THE UNIVERSITY

g-1/RL 


\section{ABSTRACT \\ EVALUATING MONITORING PRACTICES OF COMMUNITY-BASED ECOTOURISM PROJECTS \\ by Suzanne M. Behrenfeld}

A sub-sector of the tourism industry, known as ecotourism, claims to provide a mutually beneficial relationship between tourism and the environment by encouraging environmental and cultural conservation through economic incentives. This research evaluated in depth, a community-based ecotourism (CBE) project in Nepal for its success in developing the capabilities of the local communities to plan, manage, and monitor sustainable ecotourism activities. This research was expanded by evaluating the basic monitoring methods used by 15 other $\mathrm{CBE}$ projects from around the world. The final results show CBE projects can result in an equitable distribution of income from tourism, but environmental resources may not be protected well enough for long-term sustainability. 


\section{TABLE OF CONTENTS}

LIST OF FIGURES

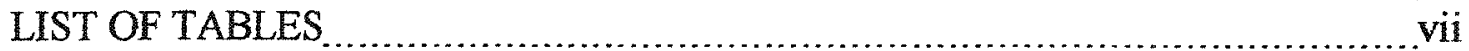

GLOSSARY OF ABBREVIAITONS ................................................. viii

CHAPTER 1: INTRODUCTION

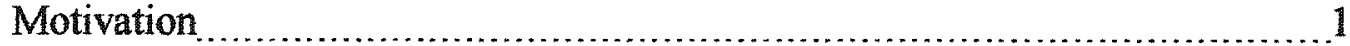

Ecotourism and Sustainability .................................................... 2

Tourism in Nepal .............................................................. 5

Problem Statement: Thesis Objectives and Research Questions.................11

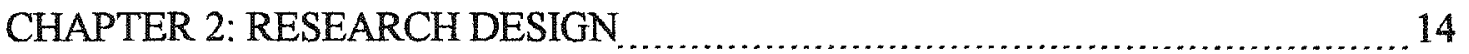

Case Study Site: The Langtang National Park and Buffer Zone, Nepal ........... 14

Methods - General ................................................................ 17

Methods - Specific

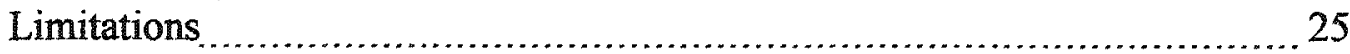

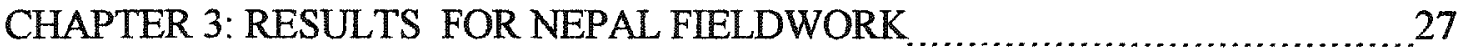

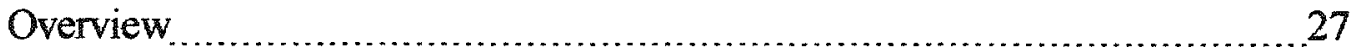

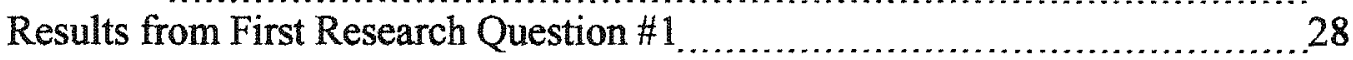

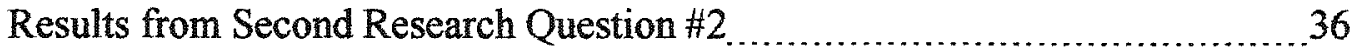

CHAPTER 4: RESULTS FOR 15 INTERNATIONAL CBE PROJECTS ..............53

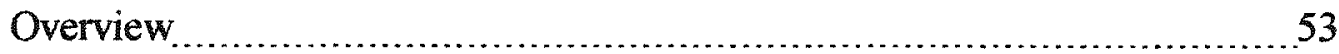

Results from Third Research Question .......................................... 53

CHAPTER 5: CONCLUSIONS AND RECOMMENDATIONS ....................56

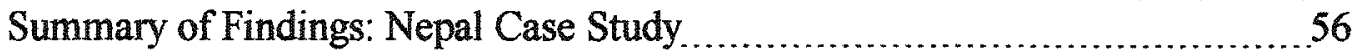

Summary of Findings: International CBE Responses ...........................61

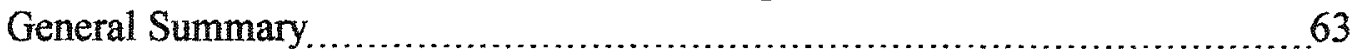

CBE Management Recommendations

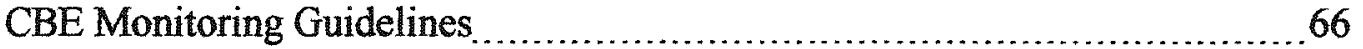

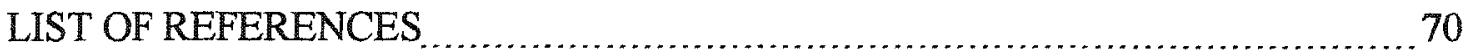

LIST OF APPENDICES

A. Participatory Learning and Action and Appreciative Inquiry ...................... 74

B. Observational Matrices for LEP Villages ..................................... 77

C. Descriptions of Observational Rankings ......................................... 92

D. Interview Questions and Responses ............................................. 93

E. Responses from CBE Facilitators ................................................... 114 


\section{LIST OF FIGURES}

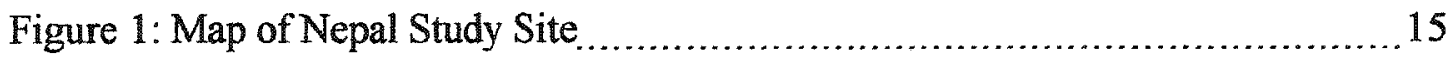

Figure 2: Photo of the Langtang National Park and Himalayan Range ....................16

Figure 3: Photo of Mr. Temba Lama Dong conducting interview......................... 19

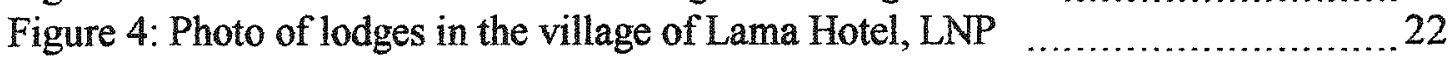

\section{LIST OF TABLES}

Table 1-1: Indicators for Lodge Management Practices and Community

Ecotourism Practices

Table 1-2: Success Categories for One-Year and Five-Year Project Goals .............. 31

Table 2-1: Satisfaction with the LEP _................................................... 38

Table 2-2: Social Impacts from Ecotourism ................................................ 41

Table 2-3: Environmental Impacts from Ecotourism ..................................... 45

Table 2-4: Economic Impacts from Ecotourism............................................ 48

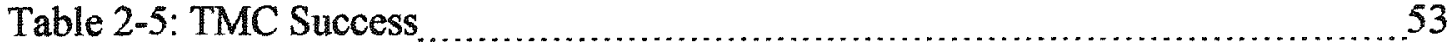




\section{GLOSSARY OF ABBREVIATIONS}

$\begin{array}{ll}\text { AI - } & \text { Appreciate Inquiry } \\ \text { CBE - } & \text { Community-Based Ecotourism } \\ \text { DDC - } & \text { District Development Committee } \\ \text { GDP - } & \text { Gross Domestic Product } \\ \text { HMG - } & \text { His Majesties Government } \\ \text { INGO - } & \text { International Nongovernmental Organization } \\ \text { IUCN - } & \text { International Union for the Conservation of Nature and Natural } \\ & \text { Resources } \\ \text { LEP - } & \text { Langtang Ecotourism Project } \\ \text { LNP - } & \text { Langtang National Park } \\ \text { NGO - } & \text { Nongovernmental Organization } \\ \text { PLA - } & \text { Participatory Learning and Action } \\ \text { TES - } & \text { The Ecotourism Society } \\ \text { TMC - } & \text { Tourism Management Committee } \\ \text { TMI - } & \text { The Mountain Institute } \\ \text { UNDP - } & \text { United Nations Development Program } \\ \text { USAID - } & \text { U.S. Agency for International Development } \\ \text { WTO - } & \text { World Tourism Organization } \\ \text { WWF - } & \text { World Wildlife Fund }\end{array}$




\section{Chapter 1: INTRODUCTION}

\section{Motivation}

As we move into the 21 st century, increasing interdependence of countries has created reliance upon cross-boundary resources. As economic globalization becomes ever stronger, economic growth in developed countries continues to be fueled in part by exploitation of resources and cheap labor in less-developed countries, creating an increasing gap between the rich and poor (Buck 1998). Tourism is viewed as a way to increase the wealth of poor nations and has become a global economic force, crossing all national boundaries and bringing costs and benefits in many forms to host countries.

Tourism is one of the largest industries of the world economy and is an important expression of globalization. By 2010, the World Tourism Organization (WTO) predicts that there will be more than US $\$ 476$ billion generated in revenue by tourism. Travel to view nature travel generates seven percent of the total international travel expenditures, and $20 \%$ in the Asia-Pacific region. The WTO estimates that $11 \%$ of the working population worldwide is employed within the tourism industry and that this industry accounts for nearly $8 \%$ of the total global Gross Domestic Product (GDP). In 2000 , there were 698 million international tourists and this number is expected to reach 1.6 billion by 2020 (WTO 2000). With this economic activity comes serious concerns about the effects of tourism on the environment and culture of host countries. Over-development of areas, increased waste, exploitation of natural resources, and cultural dilution are just a few of the issues for host countries (Rogers and Aitchison 1998). 


\section{Ecotourism and Sustainability}

In the face of these major concerns for host countries has developed a sub-sector of the tourism industry, known as ecotourism, which claims to provide a mutually beneficial relationship between tourism and the environment by encouraging cultural and environmental conservation through economic incentives. The most widely used definition of ecotourism was coined by The Ecotourism Society (1991, page 3), which defines it as "responsible travel to natural areas that conserves the environment and sustains the well-being of locals." Specifically, the main goals of ecotourism include: (1) develop greater awareness and understanding of the significant contributions that tourism can make to the environment and the economy; (2) promote equity in the sharing of development; (3) improve the quality of life of the host community; (4) provide a high quality experience for the visitor; and (5) maintain the quality of the environment on which the foregoing objectives depend (Fennel 1999).

Ecotourism is an opportunity for sustainable development in unique settings, by meeting the present needs of tourists and host regions while protecting the resources that attract tourists and serve local needs, and enhancing economic opportunities for the future. Rogers and Aitchison (1998) suggest that ecotourism should lead to the management of all resources in such a way that economic, social, and ecological needs can be fulfilled while maintaining cultural integrity, essential ecological processes, biological diversity, and life support systems (Rogers and Aitchison 1998). Successful ecotourism is ultimately sustainable tourism in unique settings that results in biodiversity and cultural conservation. 
Ecotourism is, in part, a response to the environmental and cultural costs associated with tourism. Fennel (1999) notes these reasons why the general tourism industry contradicts sustainability: "(1) Tourism is not recognized as a natural resource-dependent industry; (2) The tourism industry is invisible, especially in urban areas; (3) There is little government support, and as a result, is governmentally weak; and (4) There is a distinct lack of leadership driving the industry, which ultimately makes tourism vulnerable to poor management" (Fennel 1999, page 24). While tourism plays a vital role in today's world economy, the industry is based on a free-trade foundation with little or no management for long-term sustainability.

In contrast, ecotourism offers a platform on which to build sound management that starts in natural settings but could eventually be applied to many facets of tourism. Honey (1999) lists seven characteristics that sustainable ecotourism should exhibit: (1) involve travel to natural destinations; (2) minimize impacts; (3) build environmental awareness; (4) provide direct financial benefits for conservation; (5) provide financial benefits for local people; (6) respect local culture; and (7) support human rights and democratic movements. Ecotourism is different from adventure tourism in that it emphasizes ethical values and principles and establishes close ties to sustainable development by favoring local supply over tourist demand (Wallace 2000).

While ecotourism promises much, further investigation shows the distribution of social, environmental, and economic costs to be uneven (Fennel 1999). For example, much of what is marketed as ecotourism is simply conventional mass tourism wrapped in a thin veneer of "green." It is the use of the "ecotourism" moniker without adhering 
to the principles of ecotourism that has led to the "greenwashing" of the tourism industry (Honey 1999). Such greenwashing has created the need for more accurate monitoring so "ecotourism" projects and businesses can be evaluated as a product of sustainable environmental and cultural practice. Only then can the potential benefits this industry claims to provide be more fully realized by the local peoples and habitats.

Sustainability within the field of ecotourism involves practices that support long-term environmental and cultural conservation (Romeril 1985). Fennel (1999) argues that sustainable tourism is most likely to succeed if people of rural tourism communities work together in implementing ecotourism project goals and in sharing the benefits of improved livelihoods and conservation of resources. Ultimately, in order to be truly sustainable, communities should also take on the responsibility of managing tourism's impacts and investing in the maintenance and restoration of natural and cultural resources which are, after all, tourist attractions. Monitoring ecotourism impacts is a critical component of good management, and is an effective way to keep local peoples involved. Monitoring must be a continual process of tracking progress, and providing feedback that enables managers to adapt to changing circumstances, to identify problems, and most importantly, to provide the information needed for communities to make decisions on ways to improve conservation and livelihoods. Monitoring is also needed to follow market demand and assure an economically-viable ecotourism enterprise.

One approach to more sustainable ecotourism is through community-based ecotourism (CBE) projects. $\mathrm{CBE}$ refers to ecotourism projects and enterprises that are 
managed by the community and ideally results in a community is taking care of its natural resources in order to gain income to improve the lives of its members (Sproule 1999). A community that practices well-designed monitoring, which provides quality data and feedback, increases its capacity for effective ecotourism management. Monitoring tools adapted for local communities will promote sustainable conservation and tourism practices and will be easy to use.

Sproule (1999) has identified these four factors that show whether CBE projects encourage community conservation of natural resources: (1) the scale of benefits received by local residents and whether they outweigh the short-term costs of foregoing resource use or changing resource management; (2) the extent to which the financial benefits are clearly perceived as dependent on the resource base and therefore on sustainable management; (3) whether benefits reach all resource users; and (4) whether local institutions are strengthened so as to increase their capacities for collective management. Sproule (1999) states that massive financial earnings for a few people will not necessarily change communities' approach to resource utilization, thus emphasizing the need for economic equity within a community.

\section{Tourism in Nepal}

The Himalayan Kingdom of Nepal has been subject to many of tourism impacts on its culture and environment, which has attracted international funding for most sustainable ecotourism projects. This small country covers one-third of the entire Himalayan Range and includes ten of the fourteen highest mountains in the world, is nestled between two 
global powers, China and India. Nepal's population growth rate is one of the highest in the world at $2.6 \%$ and it ranks as one of the six poorest countries on earth. Its borders were closed to foreigners until 1949 when political pressure from India brought the need for foreign investment and protection (Moran 2000).

As a focus for international aid, Nepal has had assistance in the creation of 15 protected areas, covering $15 \%$ of its total land (Heinen and Mehta 1999). Most of these ecological projects come from the western blueprint that emphasizes preservation (Hough 1988). However, unlike most developed countries, this protected land is already inhabited, resulting in conflicting objectives when resource management approaches and local resource needs clash. As a result, solutions for successful wildlands protection in the post-industrialized countries may not be as feasible in developing nations (Bowonder 1983).

There is potential for a balance between tourism and conservation in Nepal, but increased tourism and decreasing natural resources typically moves the relationship from coexistence towards conflict (Budowski 1976, Harmon 1987). Tourism should be used and adapted to facilitate wider social, environmental, and economic development in rural and protected areas in a sustainable fashion (Rogers and Aitchison 1998). His Majesties Government (HMG) has expressed concern for the crisis in Nepal's protected areas highlighting inadequate resources for park management, poor relations between protected areas and local communities, and environmental degradation in and around parks related to tourism (HMG 1996). Several studies have specifically identified poor relations with communities living on the edges of park boundaries (Sharma 1994, Heinen 1993, Mehta 
1996). Additional concerns associated with tourism include local inequities in economic opportunities and a lack of access to tourism profits (Upadhyay 1994), the exploitation of cheap labor, and the detrimental effects of tourism on religious traditions (Scott 1994).

Some of the other environmental impacts of unmanaged tourism include litter accumulation, trail erosion, erosion-induced landslides, habitat disruption, collection or trampling of endangered plants, interrupted animal migration, and other resource depletion (Rai and Sundriyal 1997). Wildlife conservation also has its complexities related to tourism and park-people conflict. For example, in the National Parks, protected species that act as crop pests can become a nuisance to the villagers living inside and on the outskirts of a park due to increased damage to crops. Further, although rewards are given to anyone who reports a poaching incident, the fact that poachers can be imprisoned or charged substantial fines can feed the frustration of locals towards the park and Army staff, who are accustomed to hunting protected species in parks (Heinen and Mehta 1999). In Nepal, National Park forests have protection and restrictions on logging, but the increase in tourist numbers means increased fuelwood demand, shifting impacts to forests just outside park boundaries (Yonzon and Hunter 1991). Most food is cooked on wood stoves, in quantities that must satisfy the appetites of trekkers. There is also a preference to stay in lodges that are heated by a potbelly stove throughout the day and provide hot showers. Although the park requires organized trekking groups to use kerosene stoves for cooking, this applies only to tourists, not staff. A typical ecotourism group averages 12 trekkers and a support group of up to 45 porters (locals who make earnings for carrying loads from one destination to the other), all of whom use wood for 
their own personal cooking. These numbers are further exacerbated by big mountaineering expeditions, which can require up to 800 porters (Hinrichsen and Lucas 1983). These tourism pressures are resulting in forest degradation and fragmentation in Nepal's forested areas.

Socially, the local family structure is impacted by the type of labor mountain tourism requires. Porters can be away from their family for several months out of the year, which can lead to stress and break-down in families and can burden wives with extra agricultural work. Also, the work of a porter can be exceptionally taxing on the body as loads can reach between 60 and 120 pounds and are carried between eight to twelve hours a day (Cheney 1983).

Culture is inevitably affected by tourism, though the effects differ considerably with attitudes and cultural integrity. Doxey (1975) describes four main stages of reactions local people feel toward the tourism industry with the passing of time. The initial state is euphoria, when the tourist is seen as a guest, followed by apathy in which the tourist is taken for granted. This is then followed by annoyance where there is saturation in the industry and finally antagonism, where irritations are openly displayed towards tourists. The end result is that tourists start looking for a new destination due to overcrowding and hostile attitudes, leaving a previously popular destination with a degraded environment and discouraged locals who then have to find a new source of income (Budowski 1976).

The Nepalese economy brings in US $\$ 169$ million dollars a year through tourism (HMG 1996). It is estimated, however, that two-thirds of these earnings leak out of the 
economy to import goods and services from other countries to support the industry (Wells 1992). Foreigners often own land and tour companies and government officials tend to pocket revenues (Dogan 1989). Economic and intellectual leakage also result when children who study in Kathmandu or abroad do not return to the community to share their new skills.

The gap between the rich and poor is growing in the high tourist areas of Nepal. A study by Hough and Sherpa (1989) reported that much of the profit from ecotourism in the Annapurna Conservation Area goes to traditionally wealthy families who can afford to set up tea shops; this phenomenon found throughout the. This growing economic gap may indicate a need for rural development schemes integrated within the framework of reserve management to promote conservation and to allow a greater number of people to benefit from their proximity to protected areas. Most areas lag far behind the rapid pace of the legislative development needed (Heinen and Mehta 1999). True economic development is achieved when per capita income increases over a long period of time and the number below an 'absolute poverty line' does not increase, thus the distribution of income does not become more unequal (Barbier 1987).

There currently appears to be a conflict between the necessity for economic growth and that of environmental preservation. Failure to recognize this conflict can result in dangerous optimism that the relationship between the economy and environment will take care of itself, and this optimism may preclude the search for institutional solutions to the impacts of economic growth (Gowdy 1992). 
Buffer Zone management attempts to deal with tourism impacts in the area surrounding a National Park. Buffer Zone regulations were initiated by IUCN (Conservation International) in its Protected Areas Management Guidelines, which incorporates the needs of local people in reserve management. In Nepal, Buffer Zones are defined as areas adjacent to protected areas, on which land use is partially restricted. This gives an added layer of protection to the protected area itself while providing benefits to neighboring rural communities where sustainable use of natural resources is permitted. Present Nepali legislation redistributes $30-50 \%$ of the National Park entrance fee and royalties to the Buffer Zone communities (Keiter 1995).

Many stakeholder groups are involved in the success of CBE projects. These stakeholder groups include the local communities, tourism businesses, the government, Nongovernmental Organizations (NGOs), and Private Volunteer Organizations (PVOs). Involving all stakeholders in the initial financing and conservation training programs of a CBE project has shown to strengthen conservation efforts (Sproule 1999). Although some outside assistance remains after the initial programs and small business investments, the local communities are essentially responsible for the long-term success in reaching economic and conservation goals. Monitoring can help keep communities on track and involved in carrying out the main goals of CBE which are effective management of cultural and biodiversity conservation and economic equity (Sproule 1999). 
Problem Statement: Thesis Objectives and Research Questions

This research project is based on an evaluation of CBE through a case study of the Langtang Ecotourism Project (LEP) in Nepal. The LEP was supported by The Mountain Institute (TMI is an INGO based in West Virginia, USA) through a grant from USAID and worked in partnership with the Department of National Parks and Wildlife Conservation (DNPWC), a branch of His Majesty's Government (HMG) of Nepal. It was drafted as a three year project to run from 1996 to 1999 with the goal of testing a participatory based ecotourism and biodiversity conservation model (Lama 1996). This is the first evaluation of the LEP since The Mountain Institute withdrew its financial and technical support in 1999. The LEP used grass-roots methodologies known as Participatory Learning and Action (PLA) and Appreciative Inquiry (AI) (Appendix A) as tools for increasing community participation of group exercises during the planning and training activities.

The Ecotourism Society (2001) has identified four aspects of ecotourism that require monitoring. They are: (1) protected areas/biodiversity data; (2) community participation; (3) national policies for ecotourism development; and (4) international and regional policies for monitoring. Because of the importance of community involvement for ecotourism success, this research focused on evaluating community participation in monitoring and managing cultural and environmental conservation after outside stakeholders have terminated their assistance.

The first objective of this research project was to evaluate the success of the Langtang Ecotourism Project (LEP) in Nepal. To do this, the research measured the extent to which the LEP reached its primary goal of "developing the capabilities of the local communities 
inside the National Park and along trekking routes in the Buffer Zone to plan, manage, and monitor community-based ecotourism that supports biodiversity and cultural conservation in and around the Langtang National Park" (Lama 1996, page 2). This initial objective focused on measuring success from the perspective of the CBE community (or indigenous) stakeholder groups.

Because a broader context is needed for the Nepal project, the second objective of this thesis was to evaluate the monitoring methods used by $15 \mathrm{CBE}$ projects in different parts of the world. These other $\mathrm{CBE}$ projects were identified via the Internet and journal articles. In contrast to the research in Nepal that focused on indigenous CBE groups, the perspective of this global analysis was on international, or non-indigenous, stakeholder groups. Project facilitators from international CBE projects were asked to six questions regarding the monitoring methods used for the projects under their supervision.

Following the analysis and evaluation of the first two objectives, the third objective was to develop monitoring guidelines for $\mathrm{CBE}$ projects. This thesis concludes with a set of recommendations for $\mathrm{CBE}$ project monitoring that will strengthen communities ability to manage the impacts tourism has on local cultures and resources, as well as to build continuity and integrity within the ecotourism industry.

This research project is intended to benefit the communities of the Langtang National Park and Buffer Zone by increasing ecotourism success in identifying strengths and weaknesses in community planning, managing, and monitoring of ecotourism practices. On a broader scale, the final management and monitoring recommendations can be used 
as guidelines for international CBE projects and adjusted for region-specific socioeconomic and political conditions.

Working within the architecture of these three broad objectives, this thesis is guided by four fundamental research questions as follows:

1. To what extent was the LEP successful, as measured by standards set by The Mountain Institute, in developing the capabilities of the local communities in implementing ecotourism practices and goals?

2. How are community stakeholder groups of the LEP managing ecotourism through sustainable practices, promoting equity, and maintaining institutional strength, as measured by standards set by The Mountain Institute?

3. What monitoring methods are practiced by CBE projects around the world to measure ecotourism impacts?

4. What recommendations, based on this research, could improve monitoring of $\mathrm{CBE}$ projects to ensure cultural, environmental, and economic sustainability? 


\section{CHAPTER 2: RESEARCH DESIGN}

\section{Case Study Site: The Langtang National Park and Buffer Zone, Nepal}

The case study for this thesis takes place in the Langtang National Park (LNP) and Buffer Zone in the central Himalayan region of Nepal (Figure 1, page 15). The park was established in 1976 and is 1,710 square kilometers with the northern border touching the Tibet Autonomous Region of the People's Republic of China. The southern region of the park is bordered by a government-designated Buffer Zone and is part of the Helumbu Region. It is also the closest National Park to Kathmandu, which provides a close proximity for potential trekkers and greater access to goods and services for local people. The natural features that attract tourists include rhododendron forests, langur monkeys, Himalayan thar, and stunning mountain scenery (Figure 2, page 16). The peoples of the region are Yolmo and Bhotia, both originating from Tibet. They are primarily herders and farmers, but have also been involved in trans-migrant work for over 30 years, spending extended time in northern India doing manual labor. The mid-elevation region of the park is a study center of Tibetan Buddhism and the cultural heritage is kept alive through architecture, dance festivals, and weaving traditions (Lama 1996). Tourists have been coming to the region for more than 20 years with approximately 9,000 foreigners visiting annually (in recent years), and some $10-15,000$ domestic religious visitors visiting annually. As a result, tourism has played an important role in the socio-economic 
Figure 1: Map of Nepal Study Site (Yonzon and Hunter 1991)

Langtang National Park
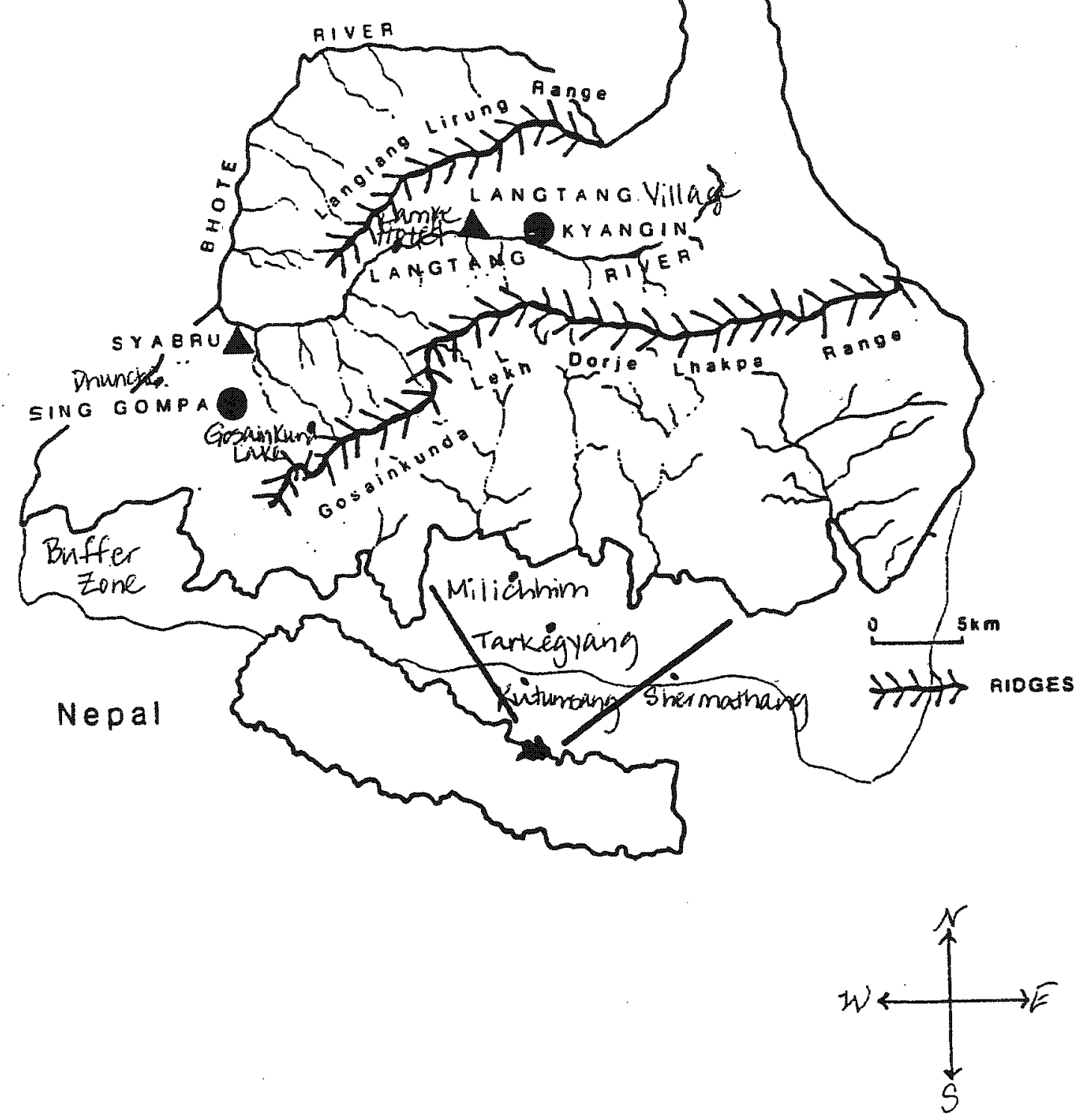
Figure 2: Photo of the Langtang National Park and Himalayan Range

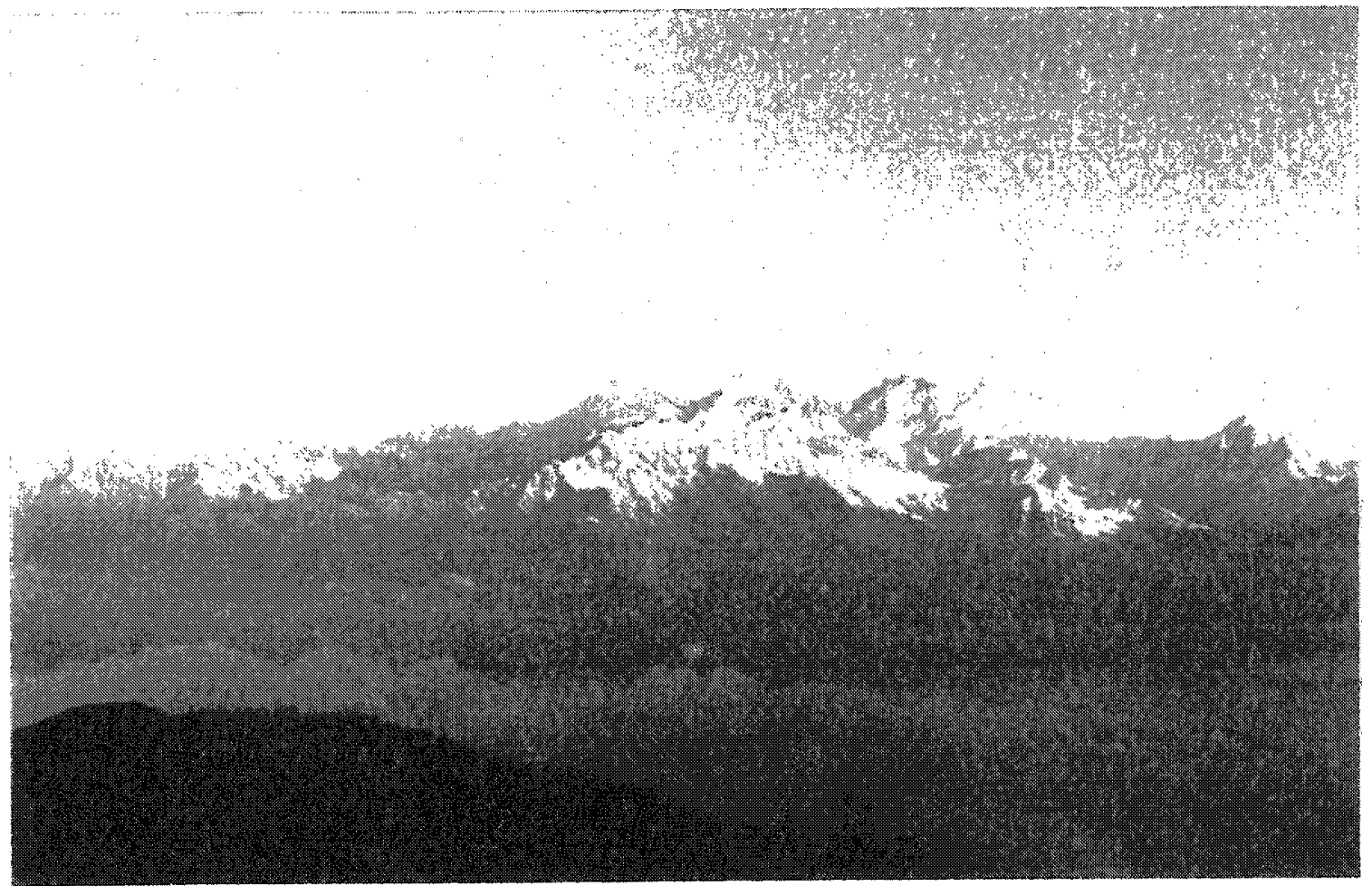

(Photo courtesy of Mr. Temba Lama Dong) 
development of the region, which has decreased dependency on other traditional activities such as grazing.

In the Langtang National Park over the past 20 years, living conditions and educational levels have risen, and there is a strong desire by the local people to restore and strengthen cultural and religious values. Local people are hesitant to seek employment away from home. This in stark contrast with the nearby Helumbu Buffer Zone region, where more than $50 \%$ of the people have migrated out to urban areas such as Kathmandu and India (Lama 1996).

\section{Methods - General}

The first research objective evaluates the Langtang Ecotourism Project's (LEP) success in reaching its primary goal of "developing the capabilities of the local communities to plan, mange, and monitor sustainable ecotourism activities". This evaluation was done in two stages: first (research question number one) by observing and ranking the capabilities of lodge owners in practicing lodge management skills, and the local community's ability to follow through with ecotourism projects initiated during the LEP, and projects planned for one and five years post LEP. Second (research question number two), community stakeholder groups were evaluated for managing cultural and natural resource conservation, economic equity, and institutional strength. Triangulation of data collection throughout the instruments of secondary data, field observations, and informal interviews are used to develop and strengthen the research framework. 
Because of current political instability in Nepal, the author was unable to conduct field research herself. Instead, a field assistant, Mr. Temba Lama Dong, was contracted through the Nepali NGO, Mountain Spirit, to conduct the field observations and informal interviews (Figure 3, page 19). As a staff member of Mountain Spirit, Mr. Dong is skilled in PRA and AI techniques from previous ecotourism work and was aware of the cultural and political sensitivities of the study area. Communication between Mr. Dong and the author was conducted via email and has been kept on file for reference.

This case study was expanded and put into context by assessing the monitoring methods used by $15 \mathrm{CBE}$ projects around the world. A total of $30 \mathrm{CBE}$ projects were identified through journal articles and the Internet, and the project facilitators were emailed for their assistance in answering six questions regarding monitoring methods practiced. Fifteen responded by agreeing to answer the questions. The analysis from the LEP evaluation and the $15 \mathrm{CBE}$ responses informed the final objective of developing monitoring guidelines for CBE projects.

\section{Methods - Specific}

The research questions and related protocol are as follows.

1. To what extent was the LEP successful, as measured by standards set by The Mountain Institute, in developing the capabilities of the local communities in implementing ecotourism practices and goals?

Secondary data were used to identify all indicators of lodge management skills taught to lodge owners and all ecotourism projects and practices initiated in villages involved in 
Figure 3: Photo of Mr. Temba Lama Dong conducting interview.

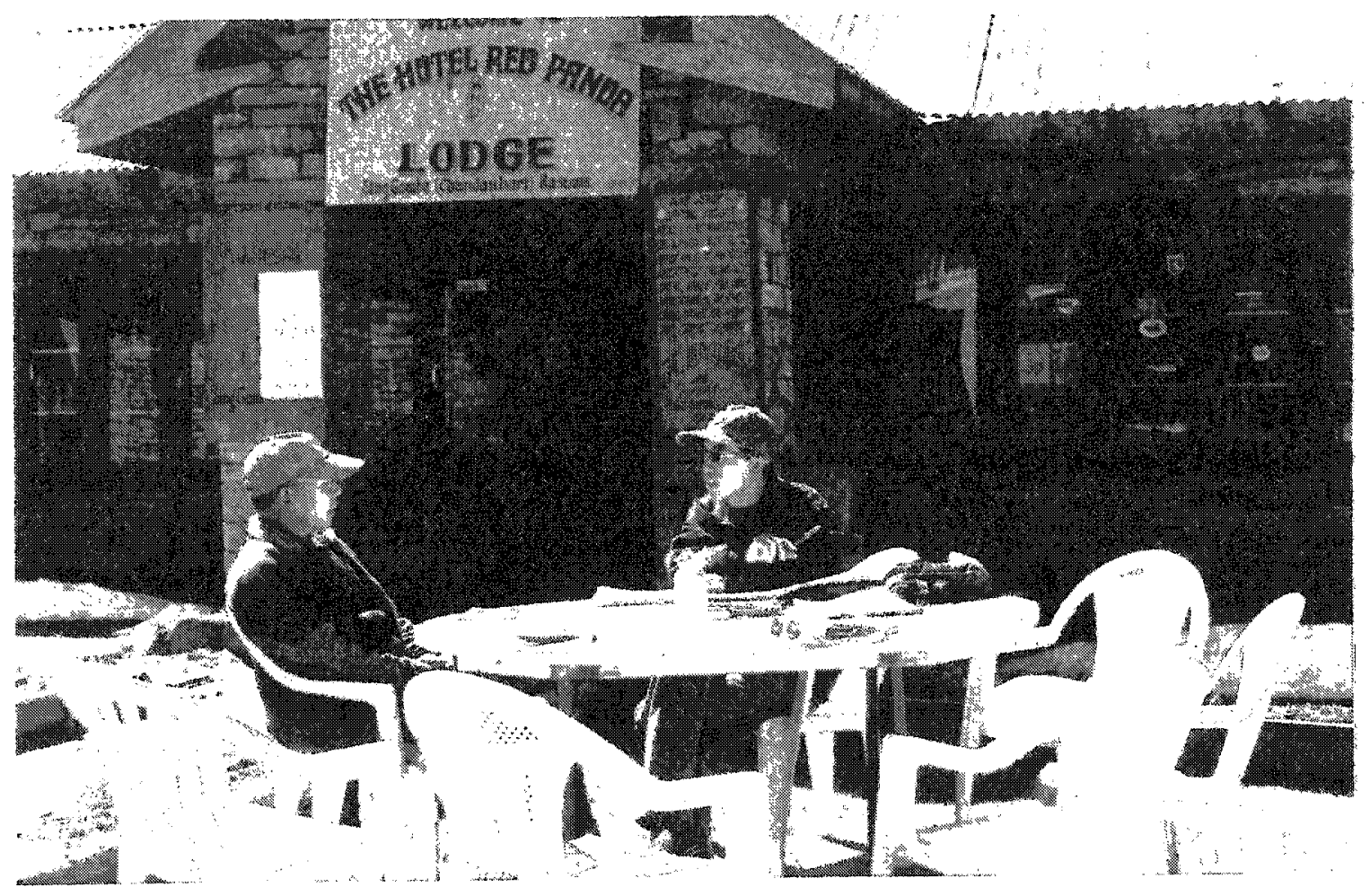

(Photo courtesy of Mr. Temba Lama Dong) 
the LEP. The sources of secondary data were three annual project reports, ten quarterly reports, and eight field and training reports written by the LEP project facilitators. These reports provided detail on the ecotourism lodge and resource management skills, participatory planning methodology, and village ecotourism plan outputs, taught and developed by LEP facilitators between 1996 and 1999. There is also a tax structure report that discusses the socio-economic situation of the project area.

A matrix for the nine villages observed was created from the data collected (See Appendix B for success indicators for each village). The villages are Dhunche, Lama Hotel, Langtang Village, Kyangzin, Sing Gompa, Melamchigyang, Tarkegyang, Shermathang, and Kutumsang. Each village's matrix includes these four categories of indicators that measure the success of conservation practices for the LEP: (1) Lodge Management Practices; (2) Community Ecotourism Practices; (3) One-Year Project Goals; and (4) Five-Year Project Goals. The matrices use non-parametric Likert Scaling from one to three for measuring each indicator. The rankings are: $1=$ unsatisfactory, $2=$ satisfactory, and $3=$ most satisfactory (evaluation criteria for rankings can be found in Appendix C). For the Lodge Management Practices evaluation, three lodges in each village were observed for their capability in practicing 17 Lodge Management Practices taught to all lodge owners during the LEP (see table 1-1, page 21, for a list of all lodge management skills). All lodge names in a village were put in a hat and three names randomly picked for the observations (Figure 4, page 22).

Ranking scores were averaged and used to analyze the success of lodge owners in practicing 17 Lodge Management Practices and of local ability to follow through with 
Table 1-1 Indicators for Lodge Management Skills and Community Ecotourism Projects

\begin{tabular}{|l|c|c|c|c|c|c|c|c|c|c|}
\hline Lodge Managment Skills & $\# 1$ & $\# 2$ & $\# 3$ & $\# 4$ & $\# 5$ & $\# 6$ & $\# 7$ & $\# 8$ & $\# 9$ & Avg. \\
\hline Garbage picked up in lodge & 3 & 3 & 3 & 3 & 2 & 3 & 3 & 3 & 3 & 3 \\
\hline Conversational English attempled & 3 & 3 & 2 & 3 & 3 & 3 & 3 & 3 & 3 & 3 \\
\hline Tourists not beckoned from trail & 2 & 3 & 2 & 2 & 3 & 3 & 1 & 1 & 3 & 2 \\
\hline Guestbook comments monitored & 1 & 1 & 1 & 1 & 1 & 2 & 1 & 1 & 1 & 1 \\
\hline Alternative fuel used for cooking & 3 & 2 & 2 & 2 & 3 & 3 & 1 & 2 & 3 & 2 \\
\hline Rubbish bin in lodge & 3 & 1 & 2 & 2 & 3 & 3 & 3 & 3 & 3 & 3 \\
\hline Toilet maintained & 3 & 2 & 3 & 3 & 3 & 3 & 3 & 3 & 3 & 3 \\
\hline Local foods offered on menu & 2 & 2 & 2 & 2 & 2 & 2 & 1 & 2 & 2 & 2 \\
\hline Fixed meal times & 1 & 1 & 1 & 2 & 1 & 1 & 1 & 1 & 2 & 1 \\
\hline Sanitary cooking methods & 3 & 2 & 3 & 2 & 2 & 3 & 3 & 3 & 3 & 3 \\
\hline Potbelly stove used & 3 & 2 & 2 & 2 & 3 & 3 & 2 & 2 & 2 & 2 \\
\hline Curtains used for insulation & 3 & 3 & 3 & 3 & 3 & 3 & 3 & 3 & 3 & 3 \\
\hline Bamboo used for insulation & 1 & 1 & 1 & 1 & 1 & 1 & 1 & 1 & 1 & 1 \\
\hline Hot showers offered & 3 & 2 & 2 & 3 & 1 & 3 & 2 & 3 & 1 & 2 \\
\hline Dining separate from kitchen & 3 & 2 & 2 & 2 & 2 & 3 & 2 & 3 & 2 & 2 \\
\hline Local decor used in lodge & 1 & 2 & 2 & 1 & 2 & 3 & 2 & 2 & 2 & 2 \\
\hline Charge for hot water & 1 & 2 & 1 & 2 & 1 & 1 & 1 & 1 & 1 & 1 \\
\hline Mean ranking for villages: & 2.25 & 1.98 & 1.9 & 2.1 & 2.06 & 2.39 & 1.96 & 2.1 & 2.02 & \\
\hline
\end{tabular}

\begin{tabular}{|l|c|c|c|c|c|c|c|c|c|c|}
\hline Community Ecotourism Projects & $\# 1$ & $\# 2$ & $\# 3$ & $\# 4$ & $\# 5$ & $\# 6$ & $\# 7$ & $\# 8$ & $\# 9$ & Avg. \\
\hline TMC meeting 2-3-months & 3 & 2 & 3 & 1 & 2 & 2 & 1 & 1 & 3 & 2 \\
\hline TMC membership fee collected & 1 & 2 & 2 & 3 & 3 & 2 & 3 & 1 & 3 & 2 \\
\hline Women's group cleaning trails & 1 & 1 & 2 & 1 & 1 & 2 & 2 & 3 & 2 & 2 \\
\hline Replanted forest managed & 2 & 2 & 2 & 2 & 2 & 1 & 2 & 2 & 3 & 2 \\
\hline Herders out of reforested area & 1 & 1 & 2 & 2 & 2 & 2 & 2 & 2 & 3 & 2 \\
\hline Kerosene sales/revenue monitored & 1 & 2 & 2 & 2 & 2 & 3 & 1 & 1 & 1 & 2 \\
\hline Fixed menu pricing & 1 & 1 & 2 & 1 & 3 & 3 & 2 & 2 & 3 & 2 \\
\hline Beditent taxes collected & 2 & 2 & 2 & 3 & 2 & 1 & 2 & 1 & 1 & 2 \\
\hline Mean ranking for villages: & 1.44 & 1.63 & 2.1 & 1.88 & 1.75 & 2 & 1.86 & 1.63 & 2.38 & \\
\hline
\end{tabular}

Rankings:

$1=$ unsatisfactory

2 = satisfactory

$3=$ most satisfactory
Village numbers:

\#1 = Dhunche

\#2 = Lama Hotel

\#3= Langtang Village

\#4 = Kyangzin

\#5 = Sing Gompa

\#6 = Melamchigyang

\#7 = Tarkegyang

$\# 8$ = Sharmathang

$\# 9=$ Kutumsang 
Figure 4: Photo of lodges in the village of Lama Hotel, LNP.

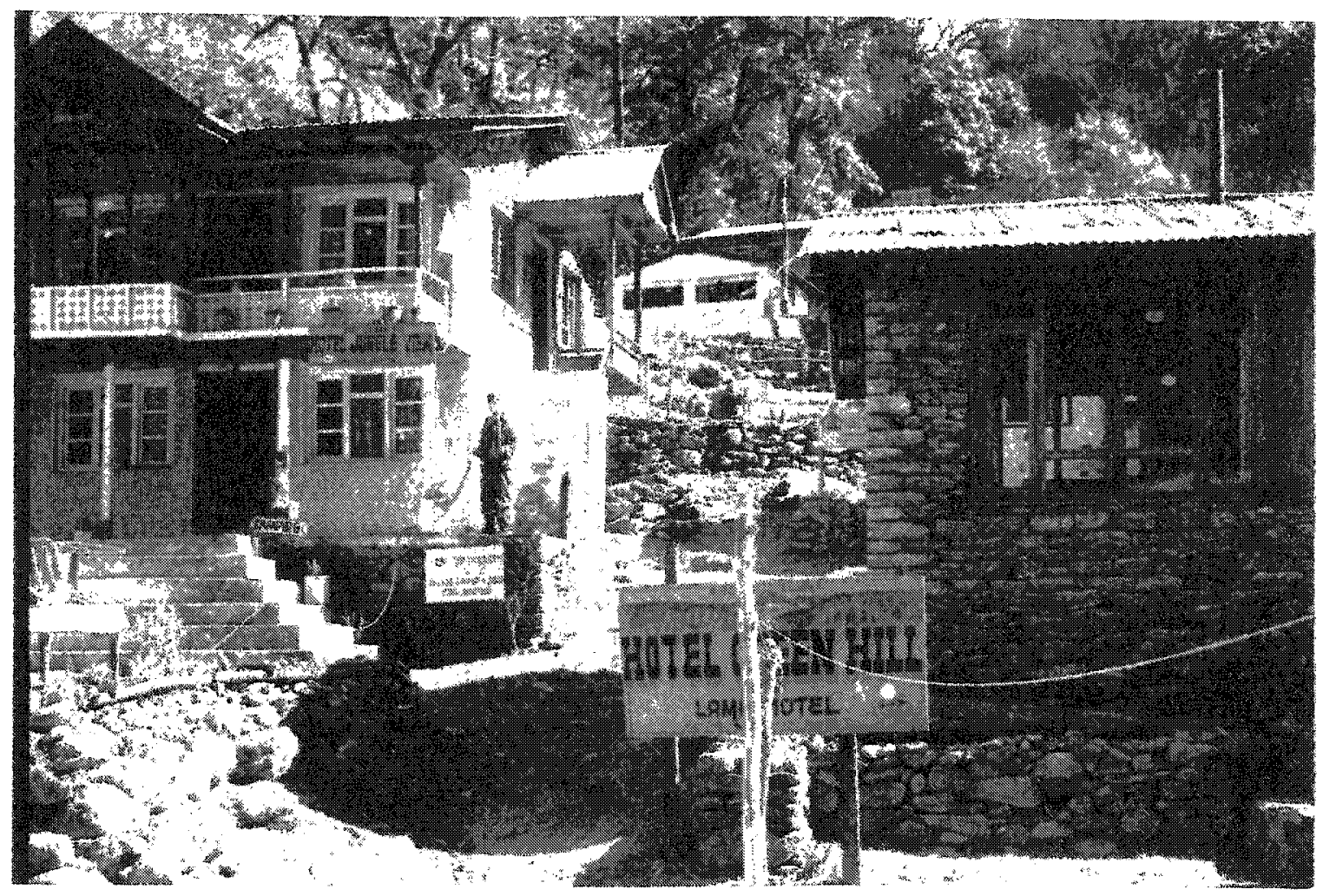

(Photo courtesy of Mr. Temba Lama Dong) 
eight Community Ecotourism Practices initiated in all 9 villages. The One-Year Project and Five-Year Project Goals were created during the LEP for the individual needs of each village and are thus site-specific indicators. For comparison purposes, the goals for each village are grouped into one of three common categories: (1) community development projects; (2) management projects; and (3) training programs. Ranking the means and percentages for each category is used to analyze success of the One-Year and Five-Year Goals. Independent variables such as local politics, village location, and socio-economic status are considered in the final discussion.

2. How are community stakeholder groups of the LEP managing ecotourism through sustainable practices, promoting equity, and developing institutional strength as measured by standards set by The Mountain Institute?

Informal interviews were conducted to answer this research question. Three community stakeholder groups were identified to evaluate the LEP success in developing economic equity and sustainable tourism practices. The stakeholder groups were: (1) lodge owners (direct tourism beneficiaries); (2) non-lodge owners (non-direct tourism beneficiaries); and (3) tourism management committees (TMC). The TMC plays an important role in a community by promoting equity between direct and nondirect beneficiaries, and carrying out ecotourism projects and management. The lodge and non-lodge interview questions were broken into social, environmental, and economic realms to find strengths and weaknesses within these three main pillars of sustainability. Equity was also evaluated through the responses of the direct and non-direct beneficiaries of the LEP. For the lodge owner representative, all the lodge names in a village were put 
in a hat and one was randomly drawn. If the lodge owner chosen was not willing to participate, another name was drawn in the same fashion. The non-lodge representatives were chosen by identifying an leader from the village user group, be it a women's group, a youth group, or forest user group. Most villages only have one of these groups.

The LEP set up a tourism management committee in all nine villages as a base for capacity building of ecotourism activities and management. A different set of interview questions was used for this third LEP community stakeholder group. The TMC interview responses helped to evaluate the institutional strength of this very important committee responsible for keeping the LEP momentum strong. The TMC chairperson (or another TMC representative if the chair person was missing) was interviewed. All interviews lasted one to two hours, followed standardized questions and pursued specific topics raised by the respondents.

The interview responses were then organized into five themes to evaluate cultural and resource conservation, economic equity, and institutional strength. Each theme has a subset of categories which follow a corresponding interview question used during the field research (interview questions and responses can be read in full detail in Appendix D). The five themes are: (1) Satisfaction with the LEP; (2) Social Impacts from Ecotourism; (3) Environmental Impacts from Ecotourism; (4) Economic Impacts from Ecotourism; and (5) Tourism Management Committee Success. For content analysis the data were organized into contingency index tables for each theme. Equity is evaluated by looking at lodge and non-lodge responses greater that $20 \%$ for each interview question. 
3. What monitoring methods are practiced by $C B E$ projects around the world to measure ecotourism impacts?

This thesis question required examining the monitoring methods used in $15 \mathrm{CBE}$ projects around the world. Facilitators for each project were contacted and asked to answer the following six questions regarding their particular project's monitoring methods:

(1) What methods are being used for monitoring the CBE project you are involved with?

(2) What issues and indicators are being monitored?

(3) When and how often is the monitoring taking place?

(4) Who is doing the monitoring?

(5) What is working and/or not working with the monitoring methods being used?

(6) If no monitoring is being done, why not?

A total of $15 \mathrm{CBE}$ project facilitators responded and answers were analyzed qualitatively. Commonalties and recommendations from the $15 \mathrm{CBE}$ projects were combined with results from the LEP evaluation to provide the information for developing the monitoring guidelines offered in the final discussion of this thesis work.

\section{Limitations}

Inevitably, this study has weaknesses, some due to the challenges of doing research in a less-industrialized country. The first limitation has been political instability in Nepal and the state-of-emergency declared in November 2001. This situation has necessarily meant 
that the author was unable to participate in the field research and personally observe the unspoken nuances and body language of respondents during the interviews, as well as to make judgments about the success of the LEP based on first-hand observations and assessments. As a result, there were several open-ended questions that, had the author been there, would have been investigated further. Some of topics the author would have sought more detail on include monitoring practices, forest and wildlife regulations and enforcement, and community political and social issues. These limitations did not invalidate the research work, as the author was able to answer all research questions. In addition, there were, most likely, subtle advantages to using a native of the area.

Considering the situation, Mr. Temba Lama Dong, the contracted assistant, did a superb job in following the instructions and put his most sincere, non-biased effort into collecting the observational data and writing the interview results exactly as they were requested. The author is confident in the field data presented in this thesis. The author believes there were many benefits in conducting the research this way. For example, respondents may have been more candid then if talking to a westerner. Also, using a local for research is in the spirit of good ecotourism practices. 


\section{CHAPTER 3: RESULTS FOR NEPAL FIELDWORK}

\section{Overview}

The field research for the LEP evaluation took place in the Langtang National Park, Nepal during the month of March, 2002. Mr. Temba Lama Dong, the contracted field assistant, conducted 27 lodge observations, 9 village observations, and 25 interviews. $\mathrm{Mr}$. Dong interviewed at total of 10 lodge representatives (a lodge representative from each of the nine villages and one additional lodge from the village of Gosainkund) and 7 nonlodge (not all villages had a non-lodge representative). A total of 8 TMC representatives were interviewed. The interview notes, along with observational rankings for the village success indicators, were sent to this researcher via email (52 pages) and edited for grammar and spelling. Photos of the study site were mailed and received in August, 2002.

For research question number one, two of the four main success indicator categories were systematically observed - Lodge Management Practices and Community Ecotourism Practices - as the variables were the same for all nine villages. An average ranking for the three lodges observed in each village was calculated for each of the 17 Lodge Management Practices. The field assistant did a ranking for each of the eight Community Ecotourism Practices by combing his observations and discussions with locals.

The One-Year and Five-Year Project Goals are considered site-specific because each village had unique and individualized goals. In order to analyze the One-Year and FiveYear Project Goals, a contingency table was created (Table 1-3) using categories common to all village goals. These are: (1) community development projects; (2) management 
projects; and (3) training programs. The total number of projects in each category are shown as a percentage and a village mean score was given for success rankings. Only five villages had data on One-Year and Five-Year Project Goals; data for the other four villages could either not be found or were never developed.

The second research question analyzes the responses of 25 volunteer interviewees to open-ended questions. The interview questions have been organized into five themes. The first four themes use the responses from the lodge (direct beneficiaries) and non-lodge (non-direct beneficiaries) community stakeholder group representatives. These themes analyze the extent to which these two community stakeholder groups are understanding and managing the social, environmental, and economic impacts of ecotourism. The final theme analyzes the success and institutional strength of each village's tourism management committee (TMC). It is important to note that the TMC carries the responsibility of distributing and managing ecotourism benefits for both direct and nondirect beneficiaries. When answers from lodge and non-lodge respondents differed by more than $20 \%$, this difference was considered "significant". Each theme has a corresponding contingency table to show interviewee response for each category in quantity and percentage (Tables 2-1 through 2-5).

\section{Results for Research Question \#1}

Observations were used in evaluating the extent to which the LEP was successful in developing lodge management skills and community ability to follow-through with ecotourism practices and projects. Table1-1 shows that while each of the eight indicators 
for the category of "Community Ecotourism Practices" averaged a ranking of 2 (satisfactory) for the project as a whole, socio-economic and political factors need to be considered to explain variations in success between the villages. For example, the villages of Dhunche, Lama Hotel, and Shermathang have the lowest success ranking totals, and villages Langtang Village, Melamchigyang, and Kutumsang had the highest. Dhunche is a road-head village with Lama Hotel not too far away. These villages have many social and political influences due to the proximity to the road, influences such as headquarters for many NGOs, the army, and the National Park. With so many concurrent political and development agendas, the focus on ecotourism project goals may not be a top priority within a village. The village of Shermathang, on the other hand, has social tension due to out-migration of youthful talent, skills, and educated leaders. This has resulted in low community initiative to plan and manage ecotourism projects. There is also low community incentive and interest in conservation of culture and resources.

The three most successful villages for Community Ecotourism Practices, Langtang Village, Melamchigyang, and Kutumsang, have had very strong TMCs' since 1999. In Langtang Village, the TMC responsibilities were recently handed over to the village Youth Club, however, the locals are planning to return the leadership back to the past TMC. This village has also unified in developing a rotating lodge system to promote economic equity and to fend off the Maoist rebels' demands for money. Both Kutumsang and Melamchigyang have had the most active 'TMCs' of all nine villages. Both maintain regular committee meetings, regulate lodge activity, raise funds for community development projects, and monitor ecotourism activities to the best of their ability. 
The three villages with average rankings showed TMC activity declining with the last year. For Sing Gomba, the TMC dissolved six months prior to the research for reasons undisclosed. The TMC in Tarkegyang was handed over to the Mothers Group and is stabilizing the management of its new responsibilities. Finally, Kyangzin is the smallest and most remote village of the LEP but had the fourth highest success ranking for Community Ecotourism Practices. Kyangzin does not have its own TMC but meets with the already strong TMC in Langtang Village, thus influencing its success.

Active TMCs appear to promote ecotourism project success, so keeping TMCs viable is a top priority. While it is difficult to say how much of an influence the Maoist Insurgency has had on the breakdown of TMCs, there is no doubt that villages have been economically effected by the resulting decline in tourism. Only the most socially united villages find ways to work together to combat any threat to their village, and strong TMCs appear to promote such strength. TMC success is apparently influenced by out-migration, proximity to a road-head, and socio-economic and political tension.

Although Community Ecotourism Practices ranked 2 for each indicator (Table 1-2), rankings for Lodge Management Practices were more varied. These variations highlight another important factor in the success of conservation practices, that being market demand. In review, the Lodge Management Practices receiving an average ranking of 3 for most satisfactory were: (1) garbage picked up in lodge; (2) conversational English attempted; (3) rubbish bin in lodge; (4) sanitary cooking methods used; (5) curtains used for insulation; and (6) toilet maintained. Lodge Management Practices ranking a 2 for satisfactory were: (1) tourists not beckoned from trail; (2) alternative fuel used for 
Table 1-2 Categories for One-Year and Five-Year Project Goals

\begin{tabular}{|c|c|c|c|c|c|c|c|c|c|c|}
\hline \multirow{3}{*}{$\begin{array}{l}\text { Village Percentages: } \\
\text { Categories } \\
\text { One year goals }\end{array}$} & \multicolumn{2}{|c|}{ Dhunche } & \multirow{2}{*}{\multicolumn{2}{|c|}{$\frac{\text { Lama } H}{\% N=4}$}} & \multirow{2}{*}{\multicolumn{2}{|c|}{$\frac{\text { Sing Gom. }}{\% N=13}$}} & \multirow{2}{*}{\multicolumn{2}{|c|}{$\begin{array}{l}\text { Tarkegy. } \\
\% \quad N=8\end{array}$}} & \multirow{2}{*}{$\begin{array}{l}\text { Shermal. } \\
\% N=15\end{array}$} & \multirow{2}{*}{$\frac{\text { Totals }}{\% N=49}$} \\
\hline & \multirow[t]{2}{*}{$\%$} & \multirow[t]{2}{*}{$N=9$} & & & & & & & & \\
\hline & & & \multirow[b]{2}{*}{0} & \multirow[b]{2}{*}{0} & \multirow[b]{2}{*}{69} & \multirow[b]{2}{*}{9} & \multirow[b]{2}{*}{50} & \multirow[b]{2}{*}{4} & & \multirow[b]{2}{*}{4120} \\
\hline Cornmunity dev. projects & 56 & 5 & & & & & & & 13 & \\
\hline Management projects & 44 & 4 & 100 & 4 & 31 & 4 & 38 & 3 & 40 & 4321 \\
\hline Training programs & 0 & 0 & 0 & 0 & 0 & 0 & 13 & 1 & 47 & 16 \\
\hline \multirow[t]{2}{*}{ Total for \% and $N$} & 100 & 9 & 100 & 4 & 100 & 13 & 100 & 8 & $100 \quad 15$ & $100 \quad 49$ \\
\hline & \multicolumn{2}{|c|}{ Dhunche } & \multicolumn{2}{|c|}{ Lama H. } & \multicolumn{2}{|c|}{ Sing Gom. } & \multicolumn{2}{|c|}{ Tarkegy. } & Shermat. & Totals \\
\hline Categories & \multicolumn{2}{|c|}{$\% \quad N=4$} & \multicolumn{2}{|c|}{$\% \quad N=9$} & \multicolumn{2}{|c|}{$\% N=10$} & \multicolumn{2}{|c|}{$\% N=10$} & $\% N=7$ & $\% N=40$ \\
\hline Five year goals & & & & & & & & & & \\
\hline Community dev. projects & 75 & 3 & 44 & 4 & 50 & 5 & 20 & 2 & 29 & $40 \quad 16$ \\
\hline Management projects & 25 & 1 & 22 & 2 & 40 & 4 & 50 & 5 & 14 & 3313 \\
\hline Training programs & 0 & 0 & 33 & 3 & 10 & 1 & 30 & 3 & 57 & 2811 \\
\hline Total for $\%$ and $N$ & 100 & 4 & 100 & 9 & 100 & 10 & 100 & 10 & 100 & 10040 \\
\hline $\begin{array}{l}\text { Village Means: } \\
\text { Categories }\end{array}$ & $\frac{\overline{D h l}}{\mathrm{me}}$ & anche & $\frac{\text { Lan }}{m}$ & $\frac{1 \mathrm{aH}}{\tan }$ & $\frac{\text { Sing }}{m}$ & $\frac{\text { Gom. }}{\tan }$ & $\begin{array}{l}\text { Tark } \\
\text { me }\end{array}$ & $\frac{\operatorname{kegy}}{\operatorname{san}}$ & $\frac{\text { Shermat. }}{\text { mean }}$ & $\frac{\text { Totals }}{\text { mean }}$ \\
\hline One year goals & & & & & & & & & & \\
\hline Community dev. & 1 & .4 & & 0 & & 2 & & .5 & 1.5 & 1.65 \\
\hline Management projects & 1 & .5 & & .5 & & .5 & & 67 & 1.83 & 1.65 \\
\hline Training $\mathrm{p}$ & t & 0 & & 0 & & 0 & & 1 & 1.86 & 1.75 \\
\hline Total Ranking: scale of 3 & 1. & 33 & & .5 & & 15 & & .5 & 1.8 & 1.73 \\
\hline Categories & $\frac{\text { Dhu }}{m e}$ & enche & $\frac{\operatorname{Lan}}{m}$ & $\frac{1 \mathrm{H} H}{\operatorname{ean}}$ & $\frac{\text { Sing }}{m}$ & $\frac{\text { Gom. }}{\operatorname{an}}$ & $\frac{\text { Tark }}{\mathrm{me}}$ & $\frac{\text { kegy. }}{\text { ean }}$ & $\frac{\text { Shermat. }}{\text { mean }}$ & $\frac{\text { Totals }}{\text { mean }}$ \\
\hline Five year goals & & & & & & & & & & \\
\hline Community dev. projects & & 1 & & 25 & & 1 & & .5 & 2 & 1.18 \\
\hline Management projects & & 2 & & 1 & & .5 & & .2 & 1.5 & 1.7 \\
\hline Training programs & & 0 & & 1 & & 1 & & 1 & 1.5 & 1.09 \\
\hline Total Ranking: scale of 3 & & 25 & & 91 & & .3 & & .2 & 1.71 & 1.3 \\
\hline
\end{tabular}


cooking; (3) local foods offered on menu; (4) potbelly stove used; (5) hot showers offered; (6) dining area separate from kitchen; and (7) local decor used in lodge. Lodge Management Skills ranking a 1 for unsatisfactory were: (1) guest book comments monitored; (2) fixed meal times; (3) charge for hot water; and (4) bamboo used for insulation.

The six indicators from the first group of most satisfactory are all qualities that tourists highly value, and may be determining factors in their selection of lodges. Thus, the local people appear to respond accordingly to "market demand". Conversational English skills put tourists at ease, and clean surroundings and sanitary cooking are some of the most sought after lodge qualities by tourists. Curtains are a successful part of lodge management not only for insulation, but also to provide privacy for guests.

The group of seven indicators for satisfactory ranking are all qualities that may be difficult to fully practice due to tourist demands. Offering local foods may be appreciated by some tourists while others may not be able to accommodate different foods or have preferences for imported foods such as packaged noodles, chocolate, and bottled beer over local brews. Heated lodges (from a potbelly stove) and hot showers lure tourists to a lodge but demand considerable fuel wood use. These lodge management skills have ranked satisfactory to reveal a market demand that promotes for lodge qualities that do not encourage optimal conservation practices. It would be necessary to interview tourists on the importance of alternative fuel use, dining separate from kitchen, and local decor in their choice of lodge. Overall, a satisfactory ranking for these indicators can be due to market demand, resource availability, or lodge owner preference. Local decor, keeping 
dining separate from the kitchen, and not beckoning tourists from the trail are all secondary importance to both lodge owners and tourists. The satisfactory ranking for these indicators shows an awareness to at least attempt these lodge management practices.

Lodge Management Practices ranking unsatisfactory were guest book comments monitored, fixed meal times, bamboo used for insulation, and charging for hot water. Fixed meal times and charging for hot water are excellent opportunities for practicing fuel wood conservation, however, tourist demand can change these priorities. Hot beverages and cooked meals throughout the day constitute some of the biggest demands from trekkers, all having different itineraries, big appetites, and sanitation needs. The impact on local forests of these two demands can be lessened with the use of alternative fuel. Although the indicator for alternative fuel use ranked satisfactory, more research is needed to decipher if there is enough alternative fuel used to lessen the burden on local forest resources.

The indicator for guest books monitored ranked unsatisfactory. This is unfortunate since most of the lodge management practices are based on tourist demand. Comments from guests could be very valuable in understanding trekkers needs and, perhaps, adjusting lodge management that can both suit the needs of guests and also local resource conservation.

Although ecotourism encourages lodge management that promotes natural resource conservation, lodge owners operate as a business enterprise with economic gain as the bottom line. Competition within the ecotourism industry can be based on environmentally-friendly practices when effectively managed through site-specific 
regulations. Increasing educational venues (through National Park staff, government, and NGOs) for trekkers on ways to support local conservation efforts would provide more economic incentive for lodges to follow sustainable lodge practices. Ideally, trekkers would encourage lodges to charge for hot water, have set meal times, and use alternative fuel as much as possible. Lodges also have the opportunity of educating trekkers by explaining the importance of such practices. Prices should accurately reflect the economic costs and benefits of services that rely on local resources.

Table 1-2 examines the One-Year and Five-Year Project Goals after the site-specific results were categorized as either (1) community development project; (2) management project; or (3) training program (see Appendix B). For One-Year Goals, $41 \%$ of the goals were community development projects, $43 \%$ were management projects, and $16 \%$ were training programs. The success ranking means were $1.65,1.65$, and 1.75 , respectively. For Five-Year Goals, $40 \%$ were community development projects, $33 \%$ were management projects, and $28 \%$ were training programs. Success ranking means dropped significantly for both community development projects (1.18) and the training programs (1.09). Overall, table 1-3 show that over time, management projects maintained success while the other two categories declined.

Management projects such as village clean-up campaigns, promotion of cultural shows, wearing traditional dress, and managing waste do not typically require great financial resources. Community development projects and training programs, on the other hand, can be a burden on community funds. Thus, the results from Table 1-2 also suggest a lack of community financial resources in carrying out project goals successfully. Projects 
where locals don't have to rely on outside resources, such as materials or trainers, can improve success simply through self-sufficiency. Training local leaders in identifying and applying for grants or other outside financial support would be a great benefit in increasing success of community short and long-term project goals. 


\section{Results for Research Question \#2}

In answering research question number two, sustainability of $\mathrm{CBE}$ projects is reached through economic equity, institutional strength, and effective management of social, environmental, and economic impacts from ecotourism. The interview responses are summarized in tables for each of the five themes; the tables highlight the strengths and weaknesses of sustainability for the LEP. All results are shown as percentages and based on data where $\mathrm{N}=10$ for lodge responses, $\mathrm{N}=7$ for non-lodge responses, and $\mathrm{N}=8$ for TMC responses.

- Theme 1: Satisfaction with the LEP

The first theme addresses villagers satisfaction with the LEP (Table 2-1). This was measured by looking at four areas: success of local ecotourism projects, villagers' involvement in LEP activities, LEP follow-up support, and understanding of ecotourism.

The three most successful projects of the LEP were lodge management training programs (59\%), kerosene depots (53\%), and village clean-up campaigns (47\%). Many of the respondents felt the lodge management training programs provided them with the necessary skills to provide quality lodge services to tourists and that the kerosene depots provided easy and affordable access to an alternative fuel source. Throughout the interviews, respondents mentioned the aesthetic and sanitation benefits of the clean-up campaigns and further, that clean villages helped to promote tourism.

Another factor indicating satisfaction was the level of involvement locals felt they had with the LEP. Of the total respondents, $76 \%$ said they were involved enough with the 
LEP, with the other two respondents expressing satisfaction with their participation for the most part. Over half $(53 \%)$ of the respondents felt that the LEP could have benefited them more through increased follow-up programs such as skill training on grant writing, monitoring tourism impacts, record keeping, and project management.

All lodge and non-lodge respondents were asked to define ecotourism and an overwhelming $88 \%$ defined ecotourism accurately as "conservation of natural resources and culture to help improve incomes and livelihood". Only two respondents answered "I don't know", but in answers to other questions, these two respondents showed a great awareness of the connection between conservation and increased income through tourism.

The only variation greater than $20 \%$ for lodge and non-lodge responses regarded lodge management training programs. The results were $70 \%$ lodge and $43 \%$ non-lodge. Nonlodge respondents are clearly lower since lodge management training programs were intended for lodge owners. Thus, a $43 \%$ response from non-lodge owners shows that indirect beneficiaries of the LEP recognize the value of good lodge management increasing tourist numbers. With more tourists staying in a village, earning potential increases for others who provide goods and services to the lodges and trekkers. 
Table 2-1 Satisfaction with the LEP

\begin{tabular}{|c|c|c|c|c|c|c|}
\hline \multirow[b]{2}{*}{ Categories } & \multicolumn{2}{|c|}{ Lodge } & \multicolumn{2}{|c|}{ Non-lodge } & \multicolumn{2}{|c|}{ Total } \\
\hline & $\%$ & $N=10$ & $\%$ & $N=7$ & $\%$ & $N=17$ \\
\hline \multicolumn{7}{|l|}{ 1. Successful ecotourism projects from the LEP* } \\
\hline Lodge management training programs & 70 & 7 & 43 & 3 & 59 & 10 \\
\hline Kerosene depot & 50 & 5 & 57 & 4 & 53 & 9 \\
\hline Clean-up campaign & 40 & 4 & 57 & 4 & 47 & 8 \\
\hline Project development & 20 & 2 & 14 & 1 & 18 & 3 \\
\hline Increased Incomes & 20 & 2 & 29 & 2 & 24 & 4 \\
\hline Conservation Improved & 20 & 2 & 29 & 2 & 24 & 4 \\
\hline \multicolumn{7}{|l|}{ 2. Satisfaction with personal involvement in the LEP } \\
\hline Yes & 70 & 7 & 86 & 6 & 76 & 13 \\
\hline Mostly & 10 & 1 & 14 & 1 & 12 & 2 \\
\hline Didn't participate, but okay & 10 & 1 & 14 & 1 & 12 & 2 \\
\hline \multicolumn{7}{|l|}{ 3. How the LEP could have met needs better } \\
\hline Follow up programs & 50 & 5 & 57 & 4 & 53 & 9 \\
\hline Not enough community involvement & 20 & 2 & 14 & 1 & 18 & 3 \\
\hline LEP was mostly beneficial & 20 & 2 & 14 & 1 & 18 & 3 \\
\hline Improved cooperation with organizations & 20 & 2 & 0 & 0 & 12 & 2 \\
\hline \multicolumn{7}{|l|}{ 4. Understanding of what ecotourism is } \\
\hline Conservation of resources for better income & 100 & 10 & 71 & 5 & 88 & 15 \\
\hline I don't know & 0 & 0 & 29 & 2 & 12 & 2 \\
\hline
\end{tabular}

Note:

* For tables $2-1$ through $2-5$ each sub-category is numbered to its corresponding interview question which can be found in Appendix D 
- Theme 2: Social Impacts from Ecotourism

Theme 2 evaluates the success of the LEP in developing community awareness and management skills in dealing with the impacts of ecotourism on social and cultural structure. Regarding livelihood improvements from ecotourism, Table 2-2 shows that of the total respondents, $88 \%$ emphasized improvement of incomes and $94 \%$ clearly felt that ecotourism caused no problems to their daily lives. Regarding cultural impact, $94 \%$ of respondents said that ecotourism helped protect their culture and that their culture experienced no negative impacts. The $6 \%$ that responded with concern about negative impacts on culture mentioned how the LEP gave daily allowances (locals were paid to attend training programs) to attendees during training programs, making it difficult to organize workshops at a low cost.

The only variation between lodge and non-lodge responses regarded improved incomes, where $100 \%$ of lodges responded and only $71 \%$ of non-lodges responded. It is important to note that all lodge responses mentioned improved income as a benefit of ecotourism. Ultimately, financial equity for an entire community would be shown with a similar response (100\%) from non-lodge owners. In this case, $71 \%$ responded that incomes had improved, which is good, but suggests opportunity for increased equity and greater LEP success.

A total of $76 \%$ of interviewees said their community has regular meetings for ecotourism planning and only $24 \%$ said their community did no obvious ecotourism planning. A total of $82 \%$ said their community monitors ecotourism impacts through opinions and discussions during the regular meetings, $12 \%$ said the TMC does the 
monitoring, and only $6 \%$ said the community has no monitoring strategies for social impacts. Little detail was provided from the field notes on the five year visions for local culture, but $82 \%$ wished it to be well preserved. Only $18 \%$ expressed a concern for the future of their culture, saying it was degrading rapidly and that they wished the community would take greater responsibility for its preservation.

The only variation between lodge and non-lodge respondents for all other questions was for the five-year vision of the culture: $100 \%$ of non-lodges and $70 \%$ of lodges wished for a well preserved culture. This difference may suggest a greater tolerance for cultural change for those receiving more economic benefits, such as lodges.

Since, apparently, the communities do not feel ecotourism has serious negative social or cultural impacts, it is not a surprise that monitoring and planning management strategies do not get much attention. Table 2-2 shows that most of the social management is done through group discussion and opinions. Managing cultural change is challenging when it is considered a sign of economic development. Although many of the Buddhist communities in Nepal are known for their cultural pride and strength, some erosion of tradition is inevitable. Managing this likely problem does not appear to be a priority with the LEP communities. 
Table 2-2 Social Impacts from Ecotourism

\begin{tabular}{|c|c|c|c|c|c|c|}
\hline \multirow[b]{2}{*}{ Categories } & \multicolumn{2}{|c|}{ Lodge } & \multicolumn{2}{|c|}{ Non-lodge } & \multicolumn{2}{|c|}{ Total } \\
\hline & $\% \Lambda$ & $V=10$ & $\%$ & $N=7$ & $\%$ & $N=17$ \\
\hline \multicolumn{7}{|l|}{ 5. Livelihood improvements from ecotourism } \\
\hline Improved the environment & 40 & 4 & 29 & 2 & 35 & 6 \\
\hline Contributed to cultural conservation & 10 & 1 & 14 & 1 & 12 & 2 \\
\hline Improved incomes & 100 & 10 & 71 & 5 & 88 & 15 \\
\hline Improved villagers skills & 30 & 3 & 29 & 2 & 30 & 5 \\
\hline \multicolumn{7}{|l|}{ 6. Livelihood problems from ecotourism } \\
\hline No problems & 100 & 10 & 86 & 6 & 94 & 16 \\
\hline Has caused problems & 0 & 0 & 14 & 1 & 6 & 1 \\
\hline \multicolumn{7}{|l|}{ 7. Cultural protection from ecotourism } \\
\hline Yes & 100 & 10 & 86 & 6 & 94 & 16 \\
\hline Concern for cultural impacts & 0 & 0 & 14 & 1 & 6 & 1 \\
\hline \multicolumn{7}{|l|}{ 8. Negative impacts on culture from ecotourism } \\
\hline No & 100 & 10 & 86 & 6 & 94 & 16 \\
\hline Concern for negative impacts & 0 & 0 & 14 & 1 & 6 & 1 \\
\hline \multicolumn{7}{|l|}{ 9. Community ecotourism planning } \\
\hline Regular meetings & 70 & 7 & 86 & 6 & 76 & 13 \\
\hline Community has made no plans & 30 & 3 & 14 & 1 & 24 & 4 \\
\hline \multicolumn{7}{|l|}{ 10. Community ecotourism monitoring } \\
\hline Opinions and discussions & 80 & 8 & 86 & 6 & 82 & 14 \\
\hline TMC does monitoring & 10 & 1 & 14 & 1 & 12 & 2 \\
\hline Community has no monitoring strategies & 10 & 1 & 0 & 0 & 6 & 1 \\
\hline \multicolumn{7}{|l|}{ 11. Five year vision of culture } \\
\hline Well preserved & 70 & 7 & 100 & 7 & 82 & 14 \\
\hline Culture is degrading; more community responsibility & 20 & 2 & 14 & 1 & 18 & 3 \\
\hline
\end{tabular}


- Theme 3: Environmental Impacts from Ecotourism

Table 2-3 addresses the Awareness of Environmental Impacts from Ecotourism. A little over half $(53 \%)$ of the respondents described the forests and wildlife as well conserved, but $41 \%$ expressed concern about misuse of forest resources by the army, National Park staff, and other people living outside the villages. Of the respondents, $82 \%$ mentioned easier accessibility to resources for livelihood as a benefit of conserving forest resources (building furniture and fuel wood use), this being a significantly greater response than that for the benefit of increased income. Respondents understood the connection between wildlife protection and increased income $(94 \%)$, but only 35 felt that wildlife was well conserved. Understanding that protecting the forest resources could increase tourism had a $47 \%$ response.

The variation between lodge and non-lodge responses was $70 \%$ and $100 \%$ respectively for forest resource accessibility. Clearly for non-lodge owners, having livelihood resources readily available is more important since their access to an alternative financial and livelihood source is less certain than the lodge owners. Perhaps the most important conclusion to be made from Table $2-3$ is that villagers are highly aware of conservation of forest and wildlife resources, but management is difficult to implement due to misconduct from management enforcers and other outside influences.

For management of environmental impacts from ecotourism, community incentive for resource conservation to be less than satisfactory. Less than half ( $41 \%)$ of the respondents said most of the community was interested in conserving resources, while the rest of the respondents (59\%) showed concern that their community was only partially 
interested in resource conservation. The awareness level, on the other hand, of income generation through resource conservation practices promoted through ecotourism is high (Table $2-4$ ) and $82 \%$ of respondents want their environment to be in good condition in five years. This sort of community contradiction - that of knowing the benefits of conservation but having low incentive for practicing it - would certainly influence conservation management. Only $12 \%$ of respondents said current resource conservation activities for forest plantations, resource regulations and fines (National Park staff and army personnel enforce park regulations), and training programs were taking place.

Varying attitudes between lodge and non-lodge respondents are clear and can help explain the previous contradiction with this theme. Non-lodge respondents gave a $43 \%$ response for a future with increased regulations, education and plantations, while only $10 \%$ of lodge owners envisaged the same. This discrepancy was also evident with the responses for current community conservation activities. Regarding regulations and fines currently taking place, $29 \%$ of non-lodge owners and $0 \%$ of lodge owners responded that they were. For forest plantations as a current conservation activity, $0 \%$ of non-lodge owners, and $20 \%$ of lodges responded in the affirmative. Clearly, non-lodge owners are effected by regulations and fines more then lodge owners. This is interesting in light of the fact that non-lodge owners, having less access to alternative economic resources and more dependent on natural resources, would want to limit any sources of livelihood through regulations. This may suggest favoritism in regulation delegation, with advantages and exceptions given to community members with more clout (typically those with more money such as lodges). Consequently, those who depend more on these 
resources see the need for improved regulation enforcement to promote resource equity. Respondents mentioned during the interviews that outside influences, such as the local army, were careless in killing wildlife and that the army had no restrictions on fuel wood use. A large army staff putting added pressure on slow growing timber resources (due to altitude) is a significant impact and an issue needing government intervention. 
Table 2-3 Environmental Impacts from Ecotourism

\begin{tabular}{|c|c|c|c|c|c|c|}
\hline \multirow[b]{2}{*}{ Categories } & \multicolumn{2}{|c|}{ Lodge } & \multicolumn{2}{|c|}{ Non-todge } & \multicolumn{2}{|c|}{ Total } \\
\hline & \multicolumn{2}{|c|}{$\% N=10$} & \multicolumn{2}{|c|}{$\% \quad N=7$} & \multicolumn{2}{|c|}{$\% \overline{N=17}$} \\
\hline \multicolumn{7}{|l|}{ 12. Conserved natural resources } \\
\hline Forests & 50 & 5 & 57 & 4 & 53 & 9 \\
\hline Wildife & 40 & 4 & 29 & 2 & 35 & 6 \\
\hline Difficult to conserve due to outside influences & 40 & 4 & 43 & 3 & 41 & 7 \\
\hline \multicolumn{7}{|l|}{ 13. Benefits of conserving wildife } \\
\hline Increased incomes & 100 & 10 & 86 & 6 & 94 & 16 \\
\hline Helps with endangered species & 0 & 0 & 14 & 1 & 6 & 1 \\
\hline \multicolumn{7}{|l|}{ 14. Benefits of conserving the forests } \\
\hline Livelihood resources more easily found & 70 & 7 & 100 & 7 & 82 & 14 \\
\hline Increased tourism & 50 & 5 & 43 & 3 & 47 & 8 \\
\hline Improved environmental conditions & 70 & 7 & 43 & 3 & 59 & 10 \\
\hline \multicolumn{7}{|l|}{ 15. Community incentive to conserve resources } \\
\hline Some yes, some no & 40 & 4 & 29 & 2 & 35 & 6 \\
\hline Most yes & 40 & 4 & 43 & 3 & 41 & 7 \\
\hline Only a few & 20 & 2 & 29 & 2 & 24 & 4 \\
\hline \multicolumn{7}{|l|}{ 16. Five year vision of environment } \\
\hline Good condition & 80 & 8 & 86 & 6 & 82 & 14 \\
\hline More regulations, education, plantations & 10 & 1 & 43 & 3 & 24 & 4 \\
\hline \multicolumn{7}{|l|}{ 17a. Community plans for resource conservation } \\
\hline Regular meetings & 40 & 4 & 14 & 1 & 29 & 5 \\
\hline Organize plantations & 70 & 7 & 71 & 5 & 71 & 13 \\
\hline Plan awareness programs & 10 & 1 & 0 & 0 & 6 & 1 \\
\hline No efforts made towards planning conservation & 10 & 1 & 0 & 0 & 6 & 1 \\
\hline \multicolumn{7}{|l|}{ 17b. Current community conservation activities } \\
\hline Forest plantations & 20 & 2 & 0 & 0 & 12 & 2 \\
\hline Regulations and fines & 0 & 0 & 29 & 2 & 12 & 2 \\
\hline Training programs & 10 & 1 & 14 & 1 & 12 & 2 \\
\hline
\end{tabular}


- Theme 4: Economic Impacts from Ecotourism

Of all the themes, the economic impacts of ecotourism received the most uniform responses. Table $2-4$ shows $88 \%$ stated ecotourism caused no financial problems, and similarly, ecotourism increased tourist numbers and incomes. Increased financial equity was expressed by $65 \%$ of the respondents with only $6 \%$ stating that only those who took part in the LEP training programs benefited financially. Interestingly, more non-lodge owners (71\%) than lodge owners (60\%) stated that ecotourism resulted in economic equity. Thus, non-direct beneficiaries believed more uniformly that financial equity and income levels increased with ecotourism; this type of equity is an important part of CBE success.

The only significant difference between lodge and non-lodge responses was the subcategory of improved environmental conditions as a benefit of conservation; $57 \%$ of nonlodge owners agreed while only $30 \%$ of lodge owners agreed. Once again, non-direct beneficiaries emphasized the importance of protecting natural resources as an alternative financial resource and for encourage ecotourism benefits

The LEP emphasized increasing economic equity of ecotourism benefits by increasing production of vegetables, poultry, and handicrafts. Table $2-4$ shows that, on average, just short of half $(38 \%)$ of the respondents said vegetables and handicrafts were produced and sold within the village and the other half said this production occurred outside the village. For the most part (59\%), respondents said poultry was produced outside the village due to the Buddhist culture and religion which encourages non-violence ("no killing"). For community fund raising, $71 \%$ of the respondents said the community raised funds through 
the lodges (i.e., bed/tent taxes, levies, and fines) and $12 \%$ said funds were collected from outside organizations and tourists. Thus, lodges have a large impact on community fund raising. Regarding earning equity, $71 \%$ said villagers who did not own a lodge earned an income through vegetable production, $35 \%$ said producing handicrafts, and $29 \%$ said through livestock production. A total of $18 \%$ said all the homes in the village were a lodge. Five-year financial vision had a $94 \%$ response for wanting improved incomes from conservation practices.

Lodge and non-lodge differences to mention regard poultry production and community fund raising sources. For poultry production outside a village, $80 \%$ of the lodges and $29 \%$ of the non-lodges gave this response. Several respondents detailed this by mentioning the local custom against killing as the reason for poultry production being mostly outside the village. Finding a way for local non-lodge owners to tap into this product market would improve income generation, as many trekkers request poultry for meals. Making sure locals are trained in small business may develop the confidence needed to increase entrepreneurial attempts, such as selling poultry, by non-direct beneficiaries.

Another variation was the response to lodges as a source for community fund raising. Lodge responses were $60 \%$ and non-lodge responses were $14 \%$, this being a large discrepancy. This suggests a lack of awareness from non-lodge owners regarding the financial contribution lodges offer the community. If lodges are such a strong contributor to community funds, then this encourages financial equity. There was a high responses from non-lodge respondents saying that financial equity had improved in their village. 
Table 2-4 Economic Impacts from Ecotourism

\begin{tabular}{|c|c|c|c|c|c|c|}
\hline \multirow[b]{2}{*}{ Categories } & \multicolumn{2}{|c|}{ Lodge } & \multicolumn{2}{|c|}{ Non-lodge } & \multicolumn{2}{|c|}{ Total } \\
\hline & $\%$ & $l=10$ & $\% 1$ & $N=7$ & $\% 1$ & $V=10$ \\
\hline \multicolumn{7}{|l|}{ 18. Improvements to village economy } \\
\hline Increased financial equity & 60 & 6 & 71 & 5 & 65 & 11 \\
\hline Increased incomes & 60 & 6 & 71 & 5 & 65 & 11 \\
\hline Improved quality of tourism services & 0 & 0 & 14 & 1 & 6 & 1 \\
\hline Only benefits those who took part in LEP programs & 10 & 1 & 0 & 0 & 6 & 1 \\
\hline \multicolumn{7}{|l|}{ 19. Financial/other benefits of conservation } \\
\hline Increased tourism, increased incomes & 90 & 9 & 86 & 6 & 88 & 15 \\
\hline Improve environment & 30 & 3 & 57 & 4 & 24 & 7 \\
\hline \multicolumn{7}{|l|}{ 20. Financial/other problems from ecotourism } \\
\hline No problems & 90 & 9 & 86 & 6 & 88 & 15 \\
\hline Conservation of wildlife causes crop destruction & 10 & 1 & 14 & 1 & 12 & 2 \\
\hline \multicolumn{7}{|l|}{ 21. Community fund raising sources } \\
\hline Outside organizations & 20 & 2 & 0 & 0 & 12 & 2 \\
\hline Mothers group/user group & 10 & 1 & 0 & 0 & 6 & 1 \\
\hline Lodges & 60 & 6 & 14 & 1 & 41 & 7 \\
\hline Cultural shows/tourists & 0 & 0 & 14 & 1 & 6 & 1 \\
\hline Bed/tent taxes and levies & 30 & 3 & 29 & 2 & 29 & 5 \\
\hline Fines & 10 & 1 & 14 & 1 & 12 & 2 \\
\hline \multicolumn{7}{|l|}{ 22. Vegetables, poultry, and handicrafts produced/sold } \\
\hline Vegetables, produced/sold mostly in village & 50 & 5 & 29 & 2 & 41 & 7 \\
\hline Handicrafts, produced/sold mostly in village & 30 & 3 & 43 & 3 & 35 & 6 \\
\hline Poultry, produced/sold mostly outside village & 80 & 8 & 29 & 2 & 59 & 10 \\
\hline Vegetables, produced/sold mostly in village & 40 & 4 & 43 & 3 & 41 & 7 \\
\hline Handicrafts, produced/sold mostly in village & 50 & 5 & 43 & 3 & 47 & 8 \\
\hline \multicolumn{7}{|l|}{ 23. Non-lodge owners tourism income } \\
\hline Growing vegetables & 60 & 6 & 86 & 6 & 71 & 12 \\
\hline Herding/producing livestock & 30 & 3 & 29 & 2 & 29 & 5 \\
\hline Producing/selling handicrafts & 30 & 3 & 43 & 3 & 35 & 6 \\
\hline All homes in village are a lodge & 30 & 3 & 0 & 0 & 18 & 3 \\
\hline \multicolumn{7}{|l|}{ 24. Five year financial vision } \\
\hline Conservation to increase tourism and incomes & 90 & 9 & 100 & 7 & 94 & 16 \\
\hline Plantations will help forests & 10 & 1 & 0 & 0 & 16 & 1 \\
\hline Garbage management provides clean surroundings & 10 & 1 & 0 & 0 & 16 & 1 \\
\hline
\end{tabular}


- Theme 5: TMC Success

Table 2-5 examines the strengths and weaknesses of the Tourism Management Committee. From the responses gathered, tourism management was considered the greatest success ( $88 \%)$ and community development mentioned as the other success (25\%). A total of $75 \%$ of respondents said the community appreciates the TMC activities. TMC participation of members was another strength with $88 \%$ of respondents mentioning a majority attendance. The reasons for any lack of participation being members giving priority to personal business projects and $38 \%$ saying meetings were too far a distance to travel. Decision making was typically accomplished through discussion and majority vote.

For present TMC activities, $38 \%$ mentioned development activities, down from $63 \%$ community development as past TMC activity. During the LEP, only 1 (13\%) village TMC was inactive, and presently $50 \%$ are inactive. There was a $38 \%$ response for action plans being for improved facilities and services, and $38 \%$ for improved regulations. For TMC improvements, $63 \%$ expressed concern for cooperation amongst members, $25 \%$ for capacity building, and 13\% saying there is no need for improvement. The TMC weakness, shown here as declines in active TMC committees and project follow-through, may be a result of the type of monitoring that has taken place over the last three years. For TMC monitoring practices, $25 \%$ of respondents said there was no monitoring taking place and $50 \%$ said monitoring was done through observations. The other two respondents (25\%) mentioned project completion and visitor opinion as monitoring methods. None of which demonstrates strong monitoring practice and documentation. 
Table 2.5 TMC Success

Categories $\frac{\text { TMC Total }}{\%}$

1. TMC project successes

Community development projects

$24 \quad 2$

Tourism management

887

2. TMC improvements

Capacity building

$25 \quad 2$

Cooperation amongst members

635

TMC needs no improvements

131

3. Communities impression of TMC

Appreciate TMC activities

TMC hasn't done anything

Some appreciate, others don't

$75 \quad 6$

131

131

4. Present TMC activities

Development activities

383

Imposing penalties

131

Collecting fees for trust fund

131

TMC is inactive

5. Past TMC activities

Community projects and training programs

635

Management projects

756

TMC was inactive

6. Five year vision for TMC

Conservation projects

131

Income projects/capacity building

383

Community projects

383

No goals

252

7. What are action plans

Improve facilities and services $\quad \begin{array}{ll}38 & 3\end{array}$

Improve regulations $\quad 38 \quad 3$

Fund raising $\begin{array}{ll}3 & 1\end{array}$

Collaborate with institutions $\quad \begin{array}{ll}13 & 1\end{array}$

8. Member participation

Most participate

887

Most don't participate

(Table 2-5 continued on next page) 
(Table 2-5 continued)

9. Explanation for non-participating members Meetings to far a distance

$38 \quad 3$

Priority to own business/projects

504

Participants never absent

131

10. TCM decision making

Discussion

$\begin{array}{ll}75 & 6\end{array}$

Majority vole

887

No concrete decisions made

11. Record keeping Minutes book

887

No records kept

12. Project monitoring

Completion

131

Visitors opinions

$13 \cdot 1$

Observe Impacts

504

No monitoring 
Management is not as effective without clear monitoring protocol. Effective management would involve follow-through with regulations, projects, and planning. The opinions from the direct and non-direct respondents (Tables 2-1 through 2-4) suggest a different level of success in the TMC management. Non-direct beneficiaries said there was greater need for resource regulations, and Table 1-2 shows a low level of followthrough with One-Year and Five-Year Project Goals, and planning to be satisfactory. 


\section{CHAPTER 4: RESULTS FOR 15 INTERNATIONAL CBE PROJECTS}

\section{Overview}

This section addresses research question number three and summarizes the responses from $15 \mathrm{CBE}$ projects from a number of different countries. A total of $30 \mathrm{CBE}$ projects were contacted in order to obtain the 15 viable responses. Most project facilitators responded to the email query in a few days and the information they provided on monitoring methods was qualified by the amount and type of monitoring data collected. Several respondents were helpful in offering suggestions and lessons learned in the field. The results from these 15 examples are combined with the Nepal research in developing the final monitoring guidelines and management recommendations in the final chapter.

\section{Results from Third Research Question}

A total of $15 \mathrm{CBE}$ project facilitators from around the world responded to an email research survey designed to answer the third research question in this thesis, which sought the monitoring methods of other CBE projects in measuring ecotourism impacts.

Responses from CBE projects in answering the six email questions were brief but showed both favorable interest and need for improved monitoring practices for CBE. Many respondents expressed concern for the lack of carry-over monitoring and evaluation taking place with CBE projects and several were interested in the results of this research project. Seven $\mathrm{CBE}$ facilitators said there was no formal monitoring protocol being followed for their projects. Two of these same respondents mentioned informal monitoring taking 
place by project facilitators through discussions with locals by asking for suggestions and level of satisfaction with their specific program. Two more from the same group of seven said informal monitoring was taking place by the communities. Three respondents mentioned ad hoc record keeping of visitors (i.e., country, sex, age, and length of visit) and two respondents mentioned general economic monitoring of profits and losses.

CBE projects in Namibia, Uganda, and Nepal had well organized protocols for monitoring. The CBE project in Namibia, called NACOBTA (Namibia CommunityBased Tourism Association), is a non-profit membership organization that supports communities in developing sustainable tourism enterprises. NACOBTA uses a Performance Indicator System to evaluate the following data: (1) Income and expenses; (2) Number and type of employees; (3) Training programs; (4) Record keeping status; (5) Marketing activities; and (6) Level of community based tourism enterprises. The data are collected every month, analyzed, and presented in quarterly reports to donors.

The Uganda CBE project, called UCOTA (Uganda Community Tourism Association), is an NGO set up by USAID that works with communities living near National Parks, helping them develop tourism businesses that promote conservation of culture and resources. The respondents from Uganda said their project monitoring takes place on a yearly basis when members gather for the general annual meeting. The Uganda project has each member fill out a form on baseline information that collects data on: (1) Quality of services and crafts products; (2) Contribution to community development projects/how livelihoods are improved; (3) Number of employees directly benefiting; (4) Gender division of employees and what position they hold; and (5) Income generated by an 
activity. Monitoring is minimal due to lack of staff and financial resources. The third project with monitoring protocol is the Salpa-Arun project based in Nepal. This CBE works with three different ethnic groups on a 50 kilometer trekking route that feeds into the Everest National Park. In the past, this project had field staff that collected information on: (1) visitor facilities; (2) condition of facilitates; (3) services provided; (4) access to alternative fuel sources other than wood; (5) methods of refuse disposal; and (6) waste management. Monitoring has been kept simple with easy to observe indicators due to lack of funding and staff time. Since late 2001, monitoring practices have been brought to a halt because Maoist threats made staff feel unsafe in the field and, equally important, locals do not now share much information, particularly so on income for self protection against Maoist threats for money. 


\section{CHAPTER 5: CONCLUSIONS AND RECOMMENDATIONS}

Summary of Findings: Nepal Case Study

The first objective of this research project was to evaluate the Nepal LEP in reaching its primary goal of "developing the capabilities of the local communities to plan, manage, and monitor CBE that supports biodiversity and cultural conservation in and around the LNP." The overall success of practicing lodge management skills was satisfactory, although market demand clearly influenced the level of success for specific lodge management indicators. Ideally, lodge practices include fixed meal times, alternative fuel usage, using a potbelly stove only during designated times, charges for hot water, curtains and other methods of insulation, and use of local foods. Lodge owners could institute these practices (which were taught by the LEP), but if these practices end in financial loses due to a decline in guests, lodge owners will adjust practices that bring more financial gain.. Increasing lodge management practices that promote resource conservation can be influenced by market demands and regulations that promote fair competition amongst community lodges. Encouraging the use of guest comment books would help decipher real and perceived market demand, thus influencing management that results in resource conservation and also boosts incomes.

The overall success rankings for Community Ecotourism Practices were satisfactory. Success was influenced by TMC strength and socio-economic issues. Political instability due to the Maoist insurgency had significant impact on community cohesiveness, in most cases, taking focus away from community development and conservation and placing it on 
safety and survival. It is interesting to note a significant shift in success ranking for OneYear and Five-Year Project Goals, where One-Year Goals had four satisfactory rankings and one unsatisfactory ranking and the reverse shown for the Five-Year Goals (one satisfactory, four unsatisfactory rankings). This shows a decline in success over time which is based on tourism committee strength and community incentive

This thesis research also evaluated the capabilities of local communities to monitor and manage ecotourism activities within the social, environmental, and economic realms of the project area. For the social impacts of ecotourism, planning and monitoring were done mostly through discussions. There were very few management strategies for protecting the culture. Nearly all of the respondents felt there was little social impact from ecotourism and most were satisfied with the positive effects ecotourism was having on their village. As a result, managing cultural change will not get much emphasis if most of the locals are already satisfied with the changes.

Villagers clearly understand the environmental condition, impact, and benefits of conservation. Management of natural resources, on the other hand, could be improved. Less then half of the respondents said that their local community had incentive to conserve natural resources, and very few respondents mentioned current resource conservation activities.

It is clear that planning, managing, and monitoring of natural resources needs to be strengthened. Involving a broader sector of the community in initial project training programs would also improve conservation success as several respondents mentioned that only those educated were interested in practicing conservation. Financial resources, or 
lack of, may have effected the success with community development and training programs, both involving substantial expenses. Management programs had greater success, perhaps due to lesser financial strain. Incorporating more training programs on accessing outside funding through grants and donations could help communities in accomplishing ecotourism goals. Community involvement could be encouraged through TMC meetings that promote participation from all community members.

Regarding the economic realm, respondents clearly understood the economic benefits of cultural and natural resource conservation. The LEP was also successful in improving economic equity by increasing non-direct beneficiaries involvement in vegetables and handicrafts production, and nature-guiding as alternative ways to tap into the tourism industry. Any market will have a hierarchy of beneficiaries, and the overall sense is that the LEP improved financial equity. There is most likely a correlation between economic equity in a village and community cohesiveness in following through with community development projects. The LEP promoted community projects that were financed through local taxes and levies that ideally benefited the entire village.

The TMC acts as one of the main pillars of ecotourism success, once outside facilitators discontinue their support. Management of tourism was considered one of the main successes of the committee and most respondents felt the community appreciated the TMC's activities and efforts. TMC management, however, is losing momentum since only $50 \%$ of the committees are currently active. While it is not totally clear why so many TMC's dissipated, some assumptions can be made. The decline in TMC success over the years could be contributed to the lack of follow-up programs, which was mentioned 
throughout the interviews. Village politics and socio-economic differences also contribute to tensions and disruptions with TMC committees and within a community.

Overall, the LEP had satisfactory success in reaching and maintaining its primary goal over a three year period once the project was terminated in 1999. In developing the capabilities of the local communities to plan, manage, and monitor $\mathrm{CBE}$, this case evaluation shows that most planning is done through the tourism or user-group committees, however, these committees have lost incentive and institutional strength. As a result, management has been ad hoc and implemented by a few motivated and aware community members. Interestingly, the overall effects of ecotourism seems to have had a positive impact on non-lodge owners through increased revenue, yet discrepancies in regulation enforcement increases community tensions. Equity can play an important role in promote peace in a region. Results from this research project suggest ecotourism is playing an important role in developing equity of the LEP region, but that biased regulation enforcement may be undermining local efforts towards community cohesiveness.

Presently, monitoring is based on group discussions and opinions expressed by tourists and locals; there is no official monitoring protocol for locals to follow. Developing local skills in monitoring can provide tangible measures of ecotourism impacts and promote local awareness of present environmental, social, and economic conditions that require upto-date management plans.

Consideration must be given to the political instability in Nepal over the last year and a half and how its presence may have influenced this survey. Mr. Temba Lama Dong 
mentioned that some potential interviewees were suspicious of his political motivation (i.e., possible connection with Maoist activity) and declined to participate in the interviews. Although tourism revenues have dropped substantially in the last year in Nepal, this research project focused on ecotourism practices, awareness of concepts, and management and monitoring of projects. Still, the linkages are such that the current political instability has caused a major decrease in tourism revenues, which in turn caused instability in community tourism planning and project management. Each village had its unique reaction to the political instability and decline in tourism. In some cases, the decreasing revenues had resulted in more intense competition, further increasing local tensions. Some villages, on the other hand, shifted strategies for dealing with Maoist threats by creating a lodge rotation system, where lodges take turns hosting trekkers to promote revenue sharing. This system also helps disperse any large accumulations of wealth that could be targeted by rebels. Knowing that there will always be outside forces that affect tourism, creating methods that keep TMC's stable during times of conflict (either at a community level or nationally) would provide the means for communities to work collectively in dealing with changing circumstances.

Success depends on goals. Goals can change as awareness, education, and empowerment increase. In light of these factors, success of the LEP can only be measured on a short-term basis. Long-term success, however, can at best be predicted on present motivation and understanding of ecotourism. Overall, the Nepal LEP has promoted equity, increased awareness of economic benefits of conservation, and initiated development projects that benefited communities as a whole. Unfortunately, the long- 
term success of the LEP may be jeopardized by the Maoist insurgency. Under these current conditions, the weak links in CBE project sustainability became very clear. Results from the LEP evaluation highlight the essential role the TMC plays in maintaining ecotourism success. The results also suggest that improved monitoring skills of community members will help keep ecotourism management effective and relevant to social, environmental, and economic changes.

\section{Summary of Findings: International CBE Responses}

This thesis work also evaluated 15 other ecotourism projects in less detail than the LEP evaluation. Several studies have suggested the need for improved monitoring and evaluation (The Ecotourism Society 2001) and this recommendation was strongly supported by responses received from the $15 \mathrm{CBE}$ projects. Only three of the fifteen $\mathrm{CBE}$ projects are following clear monitoring protocols that tourism impacts. Most of the projects are practicing informal monitoring based on undocumented opinions and observations. Two of the international $\mathrm{CBE}$ projects are gathering general economic data and three were keeping ad hoc records of visitors. In order to address ecotourism issues, cultural and natural resource conservation must also be factored into the equation of monitoring and management.

Another similar pattern between the LEP and other global CBE projects show that management and community development projects have declined over time. From these findings, it appears that outside assistance should not completely disappear once a CBE project has been implemented. Tourism brings development and social, environmental, 
and economic changes that local communities cannot always keep up with to maintain long-term sustainability. Keeping outside stakeholders involved with annual follow-up programs that assist communities with monitoring and managing impacts and change could greatly increase sustainable tourism.

Finally, some valuable recommendations were made from several of the global CBE respondents based on lessons they have learned in the field. One respondent advised keeping expectations low at the beginning, doing more then just web-based marketing, finding coordinators who speak the local language, and building trust with the ethnic minority groups. Another pointed out that the majority of ecotourism projects are underfunded, with funds for too short a time period. Respondent \#4 (India) re-emphasized the key importance of institutionalizing equity to ensure peace in the region. Respondent \#5 (Mexico) remarked that access to money was great for developing CBE projects, but little of the money goes to researching the consequences. Respondent \#13 (Namibia) mentioned the importance of focusing on why monitoring is done and how the results are used, by keeping clear that the goals and incentives for monitoring are to use the data in management to improve livelihoods and conservation.

From these findings it appears that outside assistance should not completely disappear once a CBE project has been implemented. Tourism brings development and social, environmental, and economic changes that local communities cannot always manage for long-term sustainability. Outside stakeholders of a $\mathrm{CBE}$ projects may need more than a two to three year time period to prepare a community to incorporate strong institutions for carrying out western models of resource and social management. The results of this study 
suggest that outside assistance is incorporated for a longer period of time with a more gradual rate of declining assistance as the locals gain the ability to increasingly function without project input. The majority of the $15 \mathrm{CBE}$ responses strongly encouraged developing community skills in monitoring that can be effectively adapted to sustainable management practices.

\section{General Summary}

Ecotourism in its optimal form can offer biodiversity and cultural conservation through economic incentives to local inhabitants through favored conditions in a protected and sustained state. But in many cases, ecotourism has fallen short in meeting these goals due to lack of proper planning, "greenwashing" of the industry, and insufficient monitoring and management strategies (Honey 1999). With sustainability motives as the core of ecotourism, several factors are needed to make an ecotourism project successful; one of the first steps is involving local communities in the process of collective responsibility.

Community-based ecotourism (CBE) refers to ecotourism enterprises that are owned and managed by the community or group of people living in the same geographic area being visited. It also means that this same community is actively involved in caring for their natural resources in order to increase incomes and improve their lives. Successful CBE combines conservation, business enterprise, and community development. The World Wildlife Foundation (WWF) has developed the following guidelines for initiating and developing CBE projects: (1) consider whether ecotourism is appropriate for a given area; (2) plan with communities and other stakeholders; (3) develop viable CBE 
projects through market and assessment; (4) strengthen the benefits to the community and the environment; (5) allocate a reasonable time-span to the project so that withdrawal of assistance does not occur too early; (6) develop an exit strategy at an early stage; (7) take care to impart know-how to local individuals and organizations throughout the course of the project; (8) maintain a strategy of long-term local ownership; and (9) make use of ongoing national or local authority and private sector support that may be ongoing.

An important step towards improving CBE success is effective planning. Building an ethical framework through set and agreed upon principles is important for ecotourism integrity. Once principles are set, guidelines can be created as suggestions for planning, monitoring, and management. These guidelines can then be used as a compass for developing regulations which are always based on site-specific indicators and standards of success (Wallace 1999). Once a CBE project has been successfully implemented the local community stakeholder groups are responsible for following through with management that promotes equity, healthy competition within a village, and environmental and cultural conservation. Monitoring provides the information needed for local communities to make appropriate management decisions.

Tourism is an important factor in globalization and has been described as one of "today's conquistadors" (McLaren 1998). An important aspect in global environmental conservation is to move beyond western blueprints and place increased importance on local knowledge and traditional methods with sound economic and environmental planning. With the "greenwashing" of ecotourism has come a need for guidelines that will improve the continuity and integrity of the industry. Empowering local communities in 
management techniques helps promote sustainability of the environment, economy, and culture. Monitoring is a critical component of management, and participatory monitoring serves to empower the community with knowledge and information needed to manage CBE. Thus, the third objective of this thesis is developing guidelines for monitoring that will improve CBE management.

\section{CBE Management Recommendations}

Several tactics that may help promote good CBE management have evolved from this thesis study. Initially, a CBE project should include budget resources for annual follow-up training programs for up to two years after the project has been implemented.

Withdrawing project support prematurely or suddenly may leave locals unprepared to deal with ecotourism issues without some guidance as they learn to operate independently. Some of these training programs would ideally focus on business skills and management, so locals could access outside funding and grant money for future independence. Increasing NGO involvement as a link between local communities and outside funding agencies, with office headquarters in the capital city. This can help bridge an important gap local people have in implementing projects that require outside trainers or resources.

Educating tourists and tour guides (through brochures, signboards, or museums) on creating market demands that encourage sustainable practices by lodges and other tour operators will positively direct supply and demand trends. It would also be beneficial for lodge owners to market their businesses as "ecotourism" so visitors understand that higher quality lodge services and prices help afford conservation practices (such as affording 
altemative fuel sources or providing curtains and bamboo for insulation). Building pride with inner-cultural heritage and ensuring equity of benefit sharing will promote peace amongst villagers and increase participation in ecotourism activities.

This thesis has especially highlighted the importance of building a TMC with institutional capabilities to weather social, economic, and political changes and encourage strong leadership. Each village TMC will have individual weaknesses. These should be observed and addressed before a CBE project terminates. Main-streaming the TMC by creating an official "office space" or registering with the local government may help legitimize committee authority in enforcing tourism regulations in a village.

Future research opportunities, working from these results, include: (1) tourist education and effect on market demand; (2) socio-economic and political influences on TMC strength; and (3) alternative fuel-use effect and benefit on forest resources; and (4) equity within the social structure of a community.

\section{CBE Monitoring Guidelines}

The fourth and final research question is answered with the following recommendations for improving monitoring of $\mathrm{CBE}$ projects that ensure cultural, environmental, and economic sustainability. These recommendations are based on the results from the first three research questions:

1. De-mystify the process of community-based ecotourism monitoring practices.

Explain to locals why and how monitoring is done and how the data can be integrated into adaptive management. This requires educational training that is best done within the 
project framework when locals can clarify any misunderstandings or deal with disagreements while an outside mediator or project facilitator is present.

2. Monitoring should be kept simple and inexpensive.

Since funding for CBE projects is typically minimal, and often non-existent once a project has been implemented, locals should feel like they have the ability to follow through with monitoring without financial concerns. Inexpensive monitoring can allow a village to hire a trained local for monitoring, giving data collection more value and professionalism. Simple monitoring means keeping variables to a minimum during the initial years that a community is without outside assistance. Some base indicators for monitoring should include tourism impacts on culture and resources, local project outputs, and quality of services.

3. A realistic schedule for monitoring should be developed.

Timely monitoring allows for more usable and comparable data. Overwhelming locals with too much monitoring could be counter-productive, yet not enough monitoring may cause a loss in momentum and interest. Site or village specific monitoring may provide the most productive results if on a quarterly or seasonal basis (depending on the indicator). Monitoring a $\mathrm{CBE}$ project as a whole could realistically be done on an annual basis during a general meeting or project gathering that includes all community stakeholders.

4. Train locals on quality record keeping for monitoring data collection.

Record keeping should be maintained for increasing local awareness of success, failures, and important changes. Data should remain unbiased during the monitoring process, leaving the evaluation and community discussions for the semi-annual and annual 
meetings. Data that is reliable, accurate, and consistently measured can help increase local awareness of success, failures, and important changes.

5 Develop the institutional capacity of at least two community stakeholder group representatives to do the monitoring.

Having one TMC member and at least one other community stakeholder group representative do the monitoring together on a timely basis will help prevent biases, encourage accuracy, and increase transparency of data collected (for example, lodge incomes or delegation of local regulations). It is essential that monitoring training be done before the CBE project is terminated, with follow-up training programs budgeted to help refine skills. If monitoring is kept simple and inexpensive, these positions could be paid for using lodge tax funds.

6. Monitoring livelihood changes and regulation indicators can help shed light on economic improvements and equity.

Realizing economic gains can be useful to entrepreneurs and donors for future budgeting and project financing. Equity promotes peace within a community, and this can keep a community working together in solving local problems and promoting ecotourism projects that increase revenues. Ecotourism will be more successful when a village is practicing revenue sharing and realizing economic gains.

7. Collect baseline data at the beginning of a project, using indicators developed by locals.

Baseline data should be collected during the beginning stages of a CBE project to be used as a measuring point for future changes. Giving locals the opportunity to identify 
issues to be monitored will help develop a sense of project ownership and increase interest in taking charge of their circumstances.

8 The following indicators can build a solid foundation for monitoring ecotourism impacts.

(1) Quality of services and facilities

(2) Contribution to community development projects

(3) Waste management methods

(4) Fuel sources used/access to alternative fuel sources

(5) Income generated and other benefits generated by ecotourism activity

(6) Gender enterprises employ and benefits offered

(7) Record keeping status

(8) Marketing activity

(9) Market demand

(10) Socio-cultural changes 


\section{LIST OF REFERENCES}

Barbier, Edward (1987). The Concept of Sustainable Economic Development. Environmental Conservation, 14 (2), pp. 101 - 110.

Bowonder, B. (1983). Environmental Management Conflicts in Developing Countries: An Analysis. Environmental Management, 7 (3), pp. $211-222$.

Buck Susan (1998). The Global Commons; An Introduction. Island Press, WA, DC.

Budowski, Gerardo (1976). Tourism and Environmental Conservation: Conflict, Coexistence, or Symbiosis? Environmental Conservation, 3 (1), pp. 27 - 31.

Cheney, M. (1983). Make the Death of a Porter Public. Bikas-Bikas: Development, pp. 306. Varanasi: Jauhari Printers.

Cooperrider, D.L. (1990). Positive Image, Positive Action: The Affirmative Basis for Organizing, Jossey-Bass, San Francisco.

Dogan, Hasan (1989). Forms of Adjustment: Socio-cultural Impacts of Tourism, Annals of Tourism Research, Vol. 16, pp. $216-236$.

Doxey, G.V. (1975). A Causation Theory of Visitor-Resident Irritants: Methodology and Research Inference. Paper presented at the TTRA Conference, San Diego, CA, pp. 195 198.

Fennel, David (1999). Ecotourism: An Introduction. Routledge; London, England.

Gowdy, John (1992). Economic Growth Versus the Environment. Environmental Conservation, 19 (2), pp. 102 - 104.

Harmon, David (1987). Cultural Diversity, Human Subsistence and the National Park Ideal. Environmental Ethics, 9, pp. 147 - 158.

Heinen, Joel (1993). Park-People Relations in Kosi Tappu Wildlife Reserve, Nepal: A Socio-economic Analysis. Environmental Conservation, 20 (1), pp. 25 - 34.

Heinen, Joel and Mehta, Jai (1999). Conceptual and Legal Issues in the Designation and Management of conservation Areas in Nepal. Environmental Conservation, 26 (4), pp. 21 -29 .

Hinrichsen, Don and Lucas, P.H. (1983). Saving Sagarmatha. Ambio, 12 (1), pp. 203 205. 
Honey, Martha (1999). Ecotourism and Sustainable Development: Who Owns Paradise? Island Press, Washington, DC, USA.

Hough, John (1988). Obstacles to Effective Management of Conflicts Between National Parks and Surrounding Human Communities in Developing Countries. Environmental Conservation, 15 (2), pp. $129-136$.

Hough, John and Sherpa, Norbu (1989). Bottom Up vs. Basic Needs: Integrating Conservation and Development in the Annapurna and Michiru Mountain Conservation Areas of Nepal and Malawi. Ambio, $18(8)$, pp. $434-441$.

HMG, Ministry of Tourism (1996). Nepal Tourism Statistics 1996. Kathmandu: HMG Nepal.

Keiter, Robert (1995). Preserving Nepal's National Parks. Ecology Law Quarterly, Vol. 22, pp. $591-658$.

Lama, Wendy Brewer (1996). The Mountain Institute Proposal for the Langtang Ecotourism Project. TMI, West Virginia.

McLaren, Deborah (1998). Rethinking Tourism and Ecotravel: The Paving of Paradise and What You Can Do To Stop It. Kumarian Press, Connecticut, USA, 1998.

Mehta, Jai (1996). Park-People Interface in Parsa Wildlife Reserve Nepal. TRI News: $A$ Journal of the Tropical Resources Institute, 15 (1), 11 - 12.

Moran, Kerry (2000). Nepal Handbook. Moon Publications, USA, 2000.

Rai, Suresh and Sundriyal, Rakesh (1997). Tourism and Biodiversity Conservation: The Sikkim Himalaya. Ambio, 26 (4), pp. 235 - 242.

Romeril, M. (1985). Tourism and the Environment: Towards a Symbiotic Relationship. International Journal of Environmental Studies, 25: 215 - 218.

Rogers and Aitchison (1998). Towards Sustainable Tourism in the Everest National Park. IUCN, England.

Scott, D (1994). Slave Wages on the Trails. Himal, 7 (1), 49 - 52.

Sharma, P. (1994). Who Climbs Who? Himal, 5 (6), 20 - 21 . 
Sproule, Keith (1999). Community-Based Ecotourism Development: Identifying Partners in the Process. Yale F\&ES Bulletin, pp. $233-250$.

The Ecotourism Society (1991). The Ecotourism Society Newsletter 1, no.1, spring 1991.

The Ecotourism Society (2001). MesoAmerican Preparatory meeting, International Year of Ecotourism, Belize City, Belize, Nov. 26-28, 2001. TES website.

Upadyay, A. (1994). Is Khumbu Garbage Tamed? Himal, 7 (5), 30 - 34.

Wallace, George (1999). Toward Principled Evaluation of Ecotourism Ventures. Yale F\& ES Bulletin, pp. $119-140$.

Wells, Michael (1992). Economic Benefits and Costs of Protected Areas in Nepal. Paper presented to the World Parks Congress, Caracas, February 1992.

WTO (2000). Tourism 2020 Vision: A New Forecast: Executive Summary. Madrid: World Tourism Organization.

Yonzon, Pralad and Hunter, Malcolm (1991). Cheese, Tourists, and Red Pandas in the Nepal Himalayas. Conservation Biology, 5 (2), pp. $196-202$. 


\section{LIST OF APPENDICES}

Appendix A: Participatory Learning and Action and Appreciate Inquiry

Appendix B: Observational Matrices and Ranking Data for LEP Villages

Appendix C: Descriptions for Observational Rankings

Appendix D: Interview Questions and Responses

Appendix E: Responses from CBE Facilitators 


\section{APPENDIX A}

\section{Participatory Learning and Action and Appreciative Inquiry}

Participatory Learning and Action (PLA), has been developed as a tool to work at a grassroots level and place importance in local ideas when creating management and development projects. It is based on the following methods (Cooperrider 1990):

1. Resource and social mapping: this participatory exercise is used to document socioeconomic and natural resource data for future village planning and monitoring. These crude maps are made on the ground using rocks, chalk and such markers to depict all landmarks in the village. Resource maps identify mountain peaks, rivers, lakes, forests, fuelwood and grass collection sites, grazing lands, etc. Social maps identify trails, service centers, lodges, campsites, water sources, etc.

2. Venn/Institutional Diagram: These diagrams note the relative importance of village institutions, and quantify use of natural resources such as fuelwood and timber use. Importance is ranked by the size of a circle and their relevance to each other by the proximity of the circles to each other. Roles and responsibilities are also described. 3. Pair Wise or Matrix Ranking: In this exercise participants rank and compare various items related to the project (i.e., local tourism). For example, tourism-related business can be ranked greatest to least in income generation to local people. The exercise is intended to build awareness of costs and benefits of various tourism activities.

4. Trend Line: Trend lines are drawn to show overall economic status of a village including education, conditions of resources, cultural traditions, out-migration and an 
analysis in the relations between such trends. For example, the relationship between a rise in economic welfare and a decline in cultural status or an increase in litter and an increase in tourists number from drop in litter in relation to increased awareness and park enforcement.

5. Seasonal Calendar: This exercise is to help participants identify primary work activities and village activities during the different seasons.

Appreciative Inquiry (AI) was initially developed in the mid 1980's in the USA as an attempt to step outside the established social science approach to organizational development which focused on identifying the problems or what is not working in a situation. Instead, Appreciative Inquiry, AI, works with 'the realm of the possible' and helps members of an organization envision a collectively desired future by focusing on the positive (Cooperrider 1990).

The basic principles of Appreciate Inquiry are

- What you look for is what you find (The question you ask determines the answer you get)

- Where you think you are going is where you end up (The power of belief, vision, faith, dream, or the 'self fulfilling prophecy')

- If we look for problems, we find more problems

- If we look for success, we find more success

- If we have faith in our dreams, we can achieve miracles.

4-D's: Discovery, Dream, Design, and Deliver 
Discovery

By asking positive questions, the focus becomes the successes of the project/organization. The more positive the questions asked, the more positive the answers. These are some of the questions asked by LEP staff:

- What was the best experience you had in your village/organization over the last year?

- What do you value most about your village/organization?

- What are the most successful activities your village/organization has performed?

- What makes you proud about your village/organization?

Dream

Close your eyes and envision what the future might look like. Use words, pictures, maps.

- How would you like your village to look like after 5/10/20 years?

- How would you like your village to be for your children?

Design

Make a future map and action plan to identify what activities are needed to accomplish the dream/vision: who, when, why how, what locals will contribute, what help is needed from outside, monitoring indicators and responsibility, etc. Prioritize activities by time and relevance.

Delivery and Reflection

- Develop a plan for an immediate action

- Do the activity

- Reflect: what went well; what could have been done better. Notice the sense of empowerment felt by taking immediate action 
Observational Matrices for LEP Villages

OBSERVATIONAL MATRIX NO. 1

Village: Dhunche

\begin{tabular}{|l|c|c|c|}
\hline Lodge Management Skills & Lodge \#1 & Lodge \#2 & Lodge \#3 \\
\hline Garbage picked up in lodge & 2 & 3 & 3 \\
\hline Conversational English attempted & 2 & 3 & 3 \\
\hline Tourists not beckoned from trail & 3 & 2 & 1 \\
\hline Guest book comments monitored & 2 & 1 & 1 \\
\hline Alternative fuel used for cooking & 3 & 3 & 3 \\
\hline Rubbish bin in lodge & 3 & 3 & 3 \\
\hline Toilet maintained & 2 & 3 & 3 \\
\hline Local foods offered on menu & 3 & 2 & 2 \\
\hline Fixed meal times & 2 & 1 & 1 \\
\hline Sanhiary cooking methods & 2 & 3 & 3 \\
\hline Potbelly stove used & 3 & 3 & 3 \\
\hline Curtains used for insulatión & 3 & 3 & 3 \\
\hline Bamboo used for insulation & 1 & 1 & 1 \\
\hline Hot showers offered & 3 & 3 & 3 \\
\hline Dining separate from kitchen & 2 & 3 & 3 \\
\hline Local decor used in lodge & 1 & 1 & 1 \\
\hline Charge for hot water & 1 & 1 & 1 \\
\hline Ranking mean for lodge mngmt. skills & 2.25 & & \\
\hline
\end{tabular}

Ranking mean for lodge mngmt. skills

2.25

\begin{tabular}{|l|c|}
\hline Projects During LEP & Village \\
\hline TMC meeting 2-3 months & 3 \\
\hline TMC membership fee collected. & 1 \\
\hline Women's group cleaning trails & 1 \\
\hline Replanted forest managed & 2 \\
\hline Livestock herders out of reforested area & 1 \\
\hline Kerosene sales/revenue monitored & 1 \\
\hline Fixed menu pricing & 1 \\
\hline Bedilent tax collected & 2 \\
\hline Ranking mean for projects during LEP & 1.44 \\
\hline
\end{tabular}

Village specific success indicators:

\begin{tabular}{|l|c|}
\hline One Year Goals & \\
\hline Establishment of public toilets $(\mathrm{d})$ & 1 \\
\hline Preservation of traditional houses $(\mathrm{m})$ & 2 \\
\hline Wearing trad. dress during festivals $(\mathrm{m})$ & 2 \\
\hline Prepare separate menu for local foods $(\mathrm{m})$ & 1 \\
\hline Manage trad. dress for cultural programs $(\mathrm{m})$ & 2 \\
\hline Est. separate hotel for trad. foods only (d) & 1 \\
\hline Set times for monastery hours, post notice $(\mathrm{d})$ & 1 \\
\hline Prepare signboards for monastery directions $(\mathrm{d})$ & 1 \\
\hline Perform plantation in public \& private lands (d) & 2 \\
\hline Ranking mean for one year goals & 1.44 \\
\hline
\end{tabular}




\section{Dhunche: Continued}

\begin{tabular}{|l|l|}
\hline Five Year Goals & \\
\hline Construction of hall in upper market (d) & 1 \\
\hline Manage drainage and canal in lower village (m) & 2 \\
\hline Construction of a bus park (station) (d) & 1 \\
\hline Construction of road to link upp. \& lower vill. (d) & 1 \\
\hline
\end{tabular}

Ranking mean for five year goals

Note:

(d) = community development project

(m) = management project

$(\mathrm{t})=$ training program 
OBSERVATIONAL MATRIXNO. 2

Village: Lama Hotel

\begin{tabular}{|l|c|c|c|}
\hline Lodge Management Skills & Lodge \#1 & Lodge \#2 & Lodge \#3 \\
\hline Garbage picked up in lodge & 3 & 3 & 3 \\
\hline Conversational English attempted & 3 & 2 & 3 \\
\hline Tourists not beckoned from trail & 3 & 3 & 2 \\
\hline Guest book comments monitored & 1 & 1 & 1 \\
\hline Alternative fuel used for cooking & 2 & 2 & 2 \\
\hline Rubbish bin in lodge & 1 & 1 & 2 \\
\hline Toilet maintained & 2 & 2 & 2 \\
\hline Local foods offered on menu & 2 & 2 & 2 \\
\hline Fixed meal times & 1 & 1 & 1 \\
\hline Sanitary cooking methods & 2 & 2 & 2 \\
\hline Potbelly stove used & 2 & 2 & 2 \\
\hline Curtains used for insulation & 3 & 2 & 3 \\
\hline Bamboo used for insulation & 1 & 1 & 1 \\
\hline Hot showers offered & 2 & 2 & 2 \\
\hline Dining separate from kitchen & 2 & 2 & 2 \\
\hline Local decor used in lodge & 2 & 2 & 3 \\
\hline Charge for hot water & 2 & 2 & 2 \\
\hline Ranking mean for lodge mngmt. skills & 1.98 & & \\
\hline
\end{tabular}

\begin{tabular}{|l|c|}
\hline Projects During LEP & Village \\
\hline TMC meeting 2-3 months & 2 \\
\hline TMC membership fee collected & 2 \\
\hline Women's group cleaning trails & 1 \\
\hline Replanted forest managed & 2 \\
\hline Livestock herders out of reforested area & 1 \\
\hline Kerosene sales/revenue monitored & 2 \\
\hline Fixed menu prices & 1 \\
\hline Bed/tent taxes collected & 2 \\
\hline Ranking mean for projects during LEP & 1.63 \\
\hline
\end{tabular}

Village specific success indicators:

\begin{tabular}{|l|l|}
\hline One Year Goals & \\
\hline Preservation of local culture and cult. artifacts $(\mathrm{m})$ & 1 \\
\hline Mngmt. of hotsprings and shelter at Pairo $(\mathrm{m})$ & 1 \\
\hline Management of kerosene depot $(\mathrm{m})$ & 3 \\
\hline Arrangements for purchasing stoves $(\mathrm{m})$ & 1 \\
\hline Ranking mean for one year goals & 1.5 \\
\hline
\end{tabular}

\begin{tabular}{|l|l|}
\hline Five Year Goals & \\
\hline Develop a site seeing spot at local pond (d) & 1 \\
\hline Build a pond at river side (d) & 1 \\
\hline Pavement of trails to Lama Hotel (d) & 2 \\
\hline
\end{tabular}


Lama Hotel: Continued

\begin{tabular}{|l|l|}
\hline Establish a museum at Lama Hotel $(d)$ & 1 \\
\hline Organize a guide training $(t)$ & 1 \\
\hline Organize a porter training $(t)$ & 1 \\
\hline Manage a study tour for the lodge owners $(m)$ & 1 \\
\hline Organize training on knitting and stitching $(t)$ & 1 \\
\hline Mngmt. for back boilers in lodges $(m)$ & 1 \\
\hline Ranking mean for five year goals & 1.11 \\
\hline
\end{tabular}

Note:

(d) = community development project

$(m)=$ management project

$(t)=$ training program 
OBSERVATIONAL MATRIXNO. 3

Village: Langtang Village

\begin{tabular}{|l|c|c|c|}
\hline Lodge Management Skills & Lodge \#1 & Lodge \#2 & Lodge \#3 \\
\hline Garbage picked up in lodge & 3 & 2 & 3 \\
\hline Conversational English attempted & 2 & 2 & 3 \\
\hline Tourists not beckoned from trail & 2 & 2 & 1 \\
\hline Guest book comments monitored & 1 & 1 & 1 \\
\hline Alternative fuel used for cooking & 2 & 1 & 2 \\
\hline Rubbish bin in lodge & 2 & 2 & 2 \\
\hline Toilet maintained & 3 & 2 & 3 \\
\hline Local foods offered on menu & 2 & 2 & 2 \\
\hline Fixed meal times & 1 & 1 & 1 \\
\hline Sanitary cooking methods & 3 & 2 & 3 \\
\hline Potbelly stove used & 2 & 1 & 2 \\
\hline Curtains used for insulation & 3 & 2 & 3 \\
\hline Bamboo used for insulation & 1 & 1 & 1 \\
\hline Hot showers offered & 2 & 2 & 2 \\
\hline Dining separate from kitchen & 2 & 2 & 2 \\
\hline Local decor used in lodge & 2 & 2 & 2 \\
\hline Charge for hot water & 1 & 1 & 1 \\
\hline Ranking mean for lodge mngmt. skills & 1.88 & & \\
\hline
\end{tabular}

\begin{tabular}{|l|c|}
\hline Projects During LEP & Village \\
\hline TMC meeting 2-3 months & 3 \\
\hline TMC membership fee collected & 2 \\
\hline Women's group cleaning trails & 2 \\
\hline Replanted forest managed & 2 \\
\hline Livestock herders out of reforested area & 2 \\
\hline Kerosene sales / revenue monitored & 2 \\
\hline Fixed menu prices & 2 \\
\hline Bed / tent taxes collected & 2 \\
\hline Ranking mean for projects during LEP & 2.13 \\
\hline
\end{tabular}

Village specific success indicators:

\begin{tabular}{|l|}
\hline One Year Goals \\
\hline One year goals not available \\
\hline No ranking mean to calculate
\end{tabular}

No ranking mean to calculate

Five Year Goals

Five year goals not available

No ranking mean to calculate 
OBSERVATIONAL MATRIX NO. 4

Village: Krangzin

\begin{tabular}{|l|c|c|c|}
\hline Lodge Management Skills & Lodge \#1 & Lodge \#2 & Lodge \#3 \\
\hline Garbage picked up in lodge & 3 & 3 & 3 \\
\hline Conversational English attempted & 3 & 2 & 3 \\
\hline Tourists not beckoned from trail & 2 & 1 & 2 \\
\hline Guest book comments monitored & 1 & 1 & 1 \\
\hline Alternative fuel used for cooking & 2 & 2 & 2 \\
\hline Rubbish bin in lodge & 2 & 2 & 3 \\
\hline Toilet maintained & 3 & 1 & 3 \\
\hline Local foods offered on menu & 2 & 2 & 2 \\
\hline Fixed meal times & 2 & 2 & 2 \\
\hline Sanitary cooking methods & 2 & 2 & 3 \\
\hline Potbelly stove used & 2 & 2 & 2 \\
\hline Curtains used for insulation & 3 & 3 & 3 \\
\hline Bamboo used for insulation & 1 & 1 & 1 \\
\hline Hot showers offered & 3 & 2 & 3 \\
\hline Dining separate from kitchen & 2 & 2 & 2 \\
\hline Local decor used in lodge & 1 & 2 & 2 \\
\hline Charge for hot water & 2 & 2 & 2 \\
\hline
\end{tabular}

Average mean for lodge mngmt. skills

2.1

\begin{tabular}{|l|c|}
\hline Projects During LEP & Village \\
\hline TMC meeting 2-3 months & 1 \\
\hline TMC membership fee collected & 3 \\
\hline Women's group cleaning trails & 1 \\
\hline Replanted forest managed & 2 \\
\hline Livestock herders out of reforested area & 2 \\
\hline Kerosene sales/revenue monitored & 2 \\
\hline Fixed menu pricing & 1 \\
\hline Bed/tent taxes collected & 3 \\
\hline
\end{tabular}

Ranking mean for projects during LEP 1.88

Village specific success indicators:

One Year Goals

One year goals not available

No ranking mean to calculate

Five Year Goals

Five year goals not available

No ranking mean to calculate 
OBSERVATIONAL MATRIX NO. 5

Sing Gompa

\begin{tabular}{|c|c|c|c|}
\hline Lodge Management Skills & Lodge \#1 & Lodge \#2 & Lodge \#3 \\
\hline Garbage picked up in lodge & 2 & $\frac{5}{2}$ & 3 \\
\hline Conversational English attempted & 3 & 2 & 3 \\
\hline Tourists not beckoned from trail & 3 & 2 & 3 \\
\hline Guest book comments monitored & 3 & 1 & 1 \\
\hline Alternative fuel used for cooking & 1 & 3 & 3 \\
\hline Rubbish bin in lodge & 3 & 3 & 2 \\
\hline Toilet maintained & 3 & 2 & 3 \\
\hline Local foods offered on menu & 2 & 2 & 2 \\
\hline Fixed meal times & 1 & 1 & 1 \\
\hline Sanitary cooking methods & 3 & 2 & 2 \\
\hline Potbelly stove used & 1 & 3 & 3 \\
\hline Curtains used for insulation & 3 & 3 & 3 \\
\hline Bamboo used for insulation & 2 & 1 & 1 \\
\hline Hot showers offered & 1 & 1 & 1 \\
\hline Dining separate from kitchen & 2 & 2 & 2 \\
\hline Local decor used in lodge & 2 & 2 & 2 \\
\hline Charge for hot water & 1 & 1 & 9 \\
\hline
\end{tabular}

Projects During LEP

TMC meeting every $2-3$ months

TMC membership fee collected

Women's group cleaning trails

Replanted forest managed

Livestock herders out of reforested area

Kerosene sales/revenue monitored

Fixed menu pricing

Bed/tent taxes collected

Ranking mean for village Village

Village specific success indicators:

\begin{tabular}{|l|l|}
\hline One Year Goals & \\
\hline Plantation program (d) & 2 \\
\hline Establishment of nursery (d) & 1 \\
\hline Relocation of lodges near holy lake (d) & 3 \\
\hline Fencing around the lake (d) & 1 \\
\hline Arrangement of garbage pit at holy lake (d) & 3 \\
\hline Construction and repair of huts at holy lake (d) & 3 \\
\hline Arrangement of camping sites (d) & 2 \\
\hline Trail maintenance (d) & 2 \\
\hline Preservation of Monastery at Sing Gompa (d) & 1 \\
\hline Clean-up campaign around the hotels (m) & 3 \\
\hline Use of traditional costumes at festivals (m) & 2 \\
\hline Sending back the empty beer bottles (m) & 2 \\
\hline Establishment of kerosene depot (m) & 3 \\
\hline
\end{tabular}

Ranking mean for village

2.15

continued 
Sing Gompa: Continued

\begin{tabular}{|l|c|}
\hline Five Year Goals & \\
\hline Management of drinking water facilities (m) & 2 \\
\hline Establishment of a school (d) & 1 \\
\hline Arrangement of washing place at holy lake (d) & 1 \\
\hline Establishment of health post (d) & 1 \\
\hline Promote Phulung Gompa as tourist site (m) & 1 \\
\hline Culture cons. through cultural shows (m) & 2 \\
\hline Work actively for the cons. of red panda (m) & 2 \\
\hline Organize training of herders (t) & 1 \\
\hline Establishment of view points at two locals (d) & 1 \\
\hline Establishment of post office in Sing Gompa (d) & 1 \\
\hline Ranking mean for five year goals & 1.3 \\
\hline
\end{tabular}

Note:

(d) = community development project

(m) = management project

$(t)=$ training program 
OBSERVATIONAL MATRIX NO. 6

Village: Milichhim Village

\begin{tabular}{|l|c|c|c|}
\hline Lodge Management Skills & Lodge \#1 & Lodge \#2 & Lodge \#3 \\
\hline Garbage picked up in lodge & 3 & 3 & 3 \\
\hline Conversational English attempted & 2 & 3 & 3 \\
\hline Tourists not beckoned from trail & 3 & 3 & 3 \\
\hline Guest book comments monitored & 2 & 2 & 2 \\
\hline Alternative fuel used for cooking & 3 & 2 & 3 \\
\hline Rubbish bin in lodge & 3 & 3 & 3 \\
\hline Toilet maintained & 2 & 3 & 3 \\
\hline Local foods offered on menu & 2 & 2 & 2 \\
\hline Fixed meal times & 1 & 1 & 1 \\
\hline Sanitary cooking methods & 2 & 3 & 3 \\
\hline Potbelly stove used & 3 & 3 & 3 \\
\hline Curtains used for insulation & 2 & 3 & 3 \\
\hline Bamboo used for insulation & 1 & 1 & 1 \\
\hline Hot showers offered & 2 & 3 & 3 \\
\hline Dining separate from kitchen & 3 & 3 & 2 \\
\hline Local decor used in lodge & 3 & 3 & 3 \\
\hline Charge for hot water & 1 & 1 & 1 \\
\hline Average mean for lodge mngmt. skills & 2.39 & & \\
\hline
\end{tabular}

\begin{tabular}{|l|c|}
\hline Projects During LEP & Village \\
\hline TMC meeting 2-3 months & 2 \\
\hline TMC membership fee collected & 2 \\
\hline Women's group cleaning trails & 2 \\
\hline Replanted forest managed & 1 \\
\hline Livestock herders out of forested area & 2 \\
\hline Kerosene sales/revenue monitored & 3 \\
\hline Fixed menu prices & 3 \\
\hline Bed/tent taxes collected & 1 \\
\hline Ranking for projects during LEP & 2 \\
\hline
\end{tabular}

Village specific success indicators:

\begin{tabular}{|l|}
\hline One Year Goals \\
\hline One year goals not available \\
\hline No ranking mean to calculate \\
\hline
\end{tabular}

Five Year Goals

Five year goals not available

No ranking mean to calculate 
OBSERVATIONAL MATRIX NO. 7

Village: Tarkegyang

\begin{tabular}{|l|c|c|c|}
\hline Lodge Management Skills & Lodge \#1 & Lodge \#2 & Lodge \#3 \\
\hline Garbage picked up in lodge & 3 & 3 & 3 \\
\hline Conversational English attempted & 3 & 3 & 3 \\
\hline Tourists not beckoned from trail & 1 & 1 & 1 \\
\hline Guest-book comments monitored & 1 & 1 & 1 \\
\hline Alternative fuel used for cooking & 1 & 2 & 1 \\
\hline Rubbish bin in lodge & 3 & 3 & 2 \\
\hline Toilet maintained & 3 & 3 & 3 \\
\hline Local foods offered on menu & 1 & 1 & 1 \\
\hline Fixed meal times & 1 & 1 & 1 \\
\hline Sanitary cooking methods & 3 & 3 & 3 \\
\hline Potbelly stove used & 1 & 3 & 2 \\
\hline Curtains used for insulation & 3 & 3 & 3 \\
\hline Bamboo used for insulation & 1 & 1 & 1 \\
\hline Hot showers offered & 3 & 2 & 2 \\
\hline Dining separate from kitchen & 2 & 2 & 2 \\
\hline Local decor used in lodge & 2 & 2 & 2 \\
\hline Charge for hot water & 1 & 1 & 1 \\
\hline
\end{tabular}

Ranking mean for lodge mngmt. skills

1.96

\begin{tabular}{|l|c|}
\hline Projects During LEP & Village \\
\hline TMC meeting 2-3 months & 1 \\
\hline TMC membership fee collected & 3 \\
\hline Women's group cleaning trails & 2 \\
\hline Replanted forest managed & 2 \\
\hline Livestock herders out of reforested area & 2 \\
\hline Kerosene sales/revenue managed & 1 \\
\hline Fixed menu prices & 2 \\
\hline Bed/tent taxes collected & 2 \\
\hline Ranking mean for projects during LEP & 1.86 \\
\hline
\end{tabular}

Ranking mean for projects during LEP 1.86

Village specific success indicators:

\begin{tabular}{|l|l|}
\hline One Year Goals & \\
\hline Mngmt. of rubbish bins (m) & 3 \\
\hline Arrangement of information boards (m) & 1 \\
\hline Perform plantation (d) & 1 \\
\hline Search for new vegetable seed varieties (d) & 2 \\
\hline Regular meetings of TMC (m) & 1 \\
\hline Organize English Language classes ( $)$ & 1 \\
\hline Construction of bridge to Tarkegyang River (d) & 1 \\
\hline Clean drinking water project for Tarkegyang (d) & 2 \\
\hline
\end{tabular}

Ranking mean for one year goals 
Tarkegyang: Continued

Five Year Goals

Organize study tour for user groups (t)

Organize study program for fruit production (t)

Improve livestock and poultry (m)

Regular meeting of Helmuli Youth Club (m)

Arrangement for weekly market (m)

Organize literacy classes $(t)$

Build public toilets (d)

Wearing of traditional clothing $(m)$

Gang-la Pass program (m)

Construction of bridge on Fang River (d)

Ranking mean for five year goals

1

1

1

2

2

1

Note:

(d) = community development project

(m) = management project

$(t)=$ training program 
OBSERVATIONAL MATRIX NO. 8

Village: Shermathang

\begin{tabular}{|l|c|c|c|}
\hline Lodge Management Skills & Lodge \#1 & Lodge \#2 & Lodge \#3 \\
\hline Garbage picked up in lodge & 3 & 3 & 2 \\
\hline Conversational English attempted & 3 & 3 & 3 \\
\hline Tourists not beckoned from trail & 1 & 1 & 1 \\
\hline Guest book comments monitored & 1 & 2 & 1 \\
\hline Alternative fuel used for cooking & 2 & 2 & 2 \\
\hline Rubbish bin in lodge & 3 & 3 & 2 \\
\hline Toilet maintained & 3 & 3 & 2 \\
\hline Local foods offered on menu & 2 & 2 & 2 \\
\hline Fixed meal times & 1 & 1 & 1 \\
\hline Sanitary cooking methods & 3 & 3 & 2 \\
\hline Potbelly stove used & 2 & 2 & 2 \\
\hline Curtains used for insulation & 3 & 3 & 3 \\
\hline Bamboo used for insulation & 1 & 1 & 1 \\
\hline Hot showers offered & 3 & 3 & 2 \\
\hline Dining separate from kitchen & 3 & 3 & 3 \\
\hline Local decor used in lodge & 2 & 2 & 2 \\
\hline Charge for hat water & 1 & 1 & 1 \\
\hline
\end{tabular}

Ranking mean for lodge mngmt. skills

2.1

\begin{tabular}{|l|c|}
\hline Projects During LEP & Village \\
\hline TMC meeting 2-3 months & 1 \\
\hline TMC membership fee collected & 1 \\
\hline Women's group cleaning trails & 3 \\
\hline Replanted forest managed & 2 \\
\hline Livestock herders out of forested area & 2 \\
\hline Kerosene sales/revenue monitored & 1 \\
\hline Fixed menu pricing & 2 \\
\hline Bed/tent tax collected & 1 \\
\hline
\end{tabular}

Ranking mean for projects during LEP 1.63

Village specific success indicators:

\begin{tabular}{|l|l|}
\hline One Year Goals & \\
\hline Organize adult literacy classes $(\mathrm{t})$ & 2 \\
\hline Organize lama classes $(\mathrm{t})$ & 3 \\
\hline Awareness program for cultural cons. $(\mathrm{t})$ & 1 \\
\hline Awareness program for garbage mngmt. $(\mathrm{t})$ & 2 \\
\hline Perform plantations in barren lands $(\mathrm{d})$ & 2 \\
\hline Reactivate forest user group $(\mathrm{m})$ & 2 \\
\hline Establishment of nursery $(\mathrm{d})$ & 1 \\
\hline Use of alternative fuel $(\mathrm{m})$ & 2 \\
\hline Organize refresher cooking training $(\mathrm{t})$ & 1 \\
\hline
\end{tabular}


OBSERVATIONAL MATRIX NO. 9

Village: Kutumsang

\begin{tabular}{|l|c|c|c|}
\hline Lodge Management Skills & Lodge \#1 & Lodge \#2 & Lodge \#3 \\
\hline Garbage picked up in lodge & 3 & 3 & 3 \\
\hline Conversational English attempted & 3 & 2 & 3 \\
\hline Tourists not beckoned from trail & 2 & 3 & 3 \\
\hline Guest book comments monitored & 1 & 1 & 1 \\
\hline Alternative fuel used for cooking & 3 & 2 & 3 \\
\hline Rubbish bin in lodge & 3 & 2 & 3 \\
\hline Toilet maintained & 3 & 2 & 3 \\
\hline Local foods offered on menu & 2 & 2 & 2 \\
\hline Fixed meal times & 2 & 2 & 2 \\
\hline Sanitary cooking methods & 3 & 2 & 3 \\
\hline Potbelly stove used & 3 & 2 & 2 \\
\hline Curtains used for insulation & 3 & 3 & 3 \\
\hline Bamboo used for insulation & 1 & 1 & 1 \\
\hline Hol showers offered & 1 & 2 & 1 \\
\hline Dining separatefrom kitchen & 2 & 3 & 2 \\
\hline Local docor used in lodge & 2 & 3 & 2 \\
\hline Charge for hot water & 2 & 1 & 1 \\
\hline
\end{tabular}

Ranking mean for todge mngmt. skills

2.22

\begin{tabular}{|l|c|}
\hline Projects During LEP & Village \\
\hline TMC meeting 2-3 months & 3 \\
\hline TMC membership fee collected & 3 \\
\hline Women's group cleaning trails & 2 \\
\hline Replanted forest managed & 3 \\
\hline Livestock herders out of reforested area & 3 \\
\hline Kerosene sales/revenue monitored & 1 \\
\hline Fixed menu pricing & 3 \\
\hline Bed/ent taxes collected & 1 \\
\hline
\end{tabular}

Ranking mean for projects during LEP 2.38

Village specific success indicators:

One Year Goals

One year goals were not available

No ranking mean to calculate

Five Year Goals

Five year goals were not available

No ranking mean to calculate 


\begin{tabular}{|l|c|}
\hline Increase tourism development in area $(\mathrm{m})$ & 1 \\
\hline Make parents aware of children's education $(\mathrm{t})$ & 2 \\
\hline Maintain and improve the public schools $(\mathrm{m})$ & 3 \\
\hline Creating local employment $(\mathrm{m})$ & 1 \\
\hline Organize English language training $(\mathrm{t})$ & 2 \\
\hline Ranking mean for one year goals & 1.8 \\
\hline
\end{tabular}

\begin{tabular}{|l|c|}
\hline Five Year Goals & \\
\hline Cultural preservation $(\mathrm{m})$ & 2 \\
\hline Organize traditional skills/crafts training $(t)$ & 2 \\
\hline Provide scholarship opp. for poor children $(t)$ & 1 \\
\hline Study tour for tea and fruit plantations $(t)$ & 1 \\
\hline Provide English teacher in public school $(t)$ & 2 \\
\hline Health post construction $(\mathrm{d})$ & 3 \\
\hline Telephone facilities in every household $(\mathrm{d})$ & 1 \\
\hline Ranking mean for five year goals & 1.71 \\
\hline
\end{tabular}

Note:

(d) = community development project

(m) = management project

$(t)=$ training program 
OBSERVATIONAL MATRIX NO. 9

Village: Kutumsang

\begin{tabular}{|l|c|c|c|}
\hline Lodge Management Skills & Lodge \#1 & Lodge \#2 & Lodge \#3 \\
\hline Garbage picked up in lodge & 3 & 3 & 3 \\
\hline Conversational English attempted & 3 & 2 & 3 \\
\hline Tourists not beckoned from trail & 2 & 3 & 3 \\
\hline Guest book comments monitored & 1 & 1 & 1 \\
\hline Alternative fuel used for cooking & 3 & 2 & 3 \\
\hline Rubbish bin in lodge & 3 & 2 & 3 \\
\hline Toilet maintained & 3 & 2 & 3 \\
\hline Local foods offered on menu & 2 & 2 & 2 \\
\hline Fixed meal times & 2 & 2 & 2 \\
\hline Sanitary cooking methods & 3 & 2 & 3 \\
\hline Potbelly stove used & 3 & 2 & 2 \\
\hline Curtains used for insulation & 3 & 3 & 3 \\
\hline Bamboo used for insulation & 1 & 1 & 1 \\
\hline Hot showers offered & 1 & 2 & 1 \\
\hline Dining separatefrom kitchen & 2 & 3 & 2 \\
\hline Local decor used in lodge & 2 & 3 & 2 \\
\hline Charge for hot water & 2 & 1 & 1 \\
\hline Ranking mean for lodge mngmt. skills & 2.22 & & \\
\hline
\end{tabular}

\begin{tabular}{|l|c|}
\hline Projects During LEP & Village \\
\hline TMC meeting 2-3 months & 3 \\
\hline TMC membership fee collected & 3 \\
\hline Women's group cleaning trails & 2 \\
\hline Replanted forest managed & 3 \\
\hline Livestock herders out of reforested area & 3 \\
\hline Kerosene sales/revenue monitored & 1 \\
\hline Fixed menu pricing & 3 \\
\hline Bed/tent taxes collected & 1 \\
\hline Ranking mean for projects during LEP & 2.38 \\
\hline
\end{tabular}

Village specific success indicators:

One Year Goals

One year goals were not available

No ranking mean to calculate

Five Year Goals

Five year goals were not available

No ranking mean to calculate 


\section{APPENDIX C}

\section{Descriptions for Observational Rankings}

Lodge Management Practices Rankings

For the columns "Lodge \#1, Lodge \#2, and Lodge \#3", the rankings will be 1 = unsatisfactory, $2=$ satisfactory, and $3=$ most satisfactory.

GARBAGE PICKED UP IN LODGE ( 1 = garbage is not picked up and lodge is not swept daily, $2=$ most of the garbage is picked up, but some is lying around, $3=$ all the garbage is picked up, the lodge is very clean and swept daily)

CONVERSATIONAL ENGLISH ATTEMPTED $(1=$ lodge owner doesn't practice English, 2 = lodge owner knows a few words, $3=$ lodge owner is actively learning English when talking to tourists, asking questions)

TOURISTS NOT BECKONED FROM TRAIL ( 1 = tourists beckoned from trail, 2 = tourists sometimes beckoned from trail, $3=$ tourists never beckoned from trail)

GUESTBOOK COMMENTS MONITORED ( 1 = there is no guest book in the lodge, $2=$ there is a guest book but not used consistently, 3 = there is a guest book and all guests are asked to sign in)

ALTERNATIVE FUEL USED FOR COOKING $(1=$ only firewood is used in lodge, $2=$ some type of kerosene or alternative fuel is used at times, $3=$ only kerosene or alternative fuel is used.)

RUBBISH BIN IN LODGE ( 1 = no rubbish bin in lodge, 2 = rubbish bin, but not used much, $3=$ rubbish bins are used often)

TOLLT MAINTAINED ( $1=$ toilet is not cleaned everyday, $2=$ toilet is cleaned every other day, 3 = toilet is cleaned every day)

LOCAL FOODS OFFERED ON MENU ( 1 = mostly Western food offered, food not bought from own village, $2=$ some Nepali dishes offered, some food bought from own village, $3=$ most dishes offered are Nepali and most food used is bought within the village)

FIXED MEAL TIMES ( $1=$ no fixed meal times offered, $2=$ fixed meal times offered but only sometimes followed, $3=$ fixed meal times offered and most of the time followed)

SANITARY COOKING METHODS USED ( 1 = hands not washed before cooking; dishes and silverware not washed with soap and not dried, $2=$ hands usually washed 
before cooking; dishes and silverware washed and dried, 3 = hands always washed before cooking; dishes and silverware washed in soapy, warm water and dried)

POTBELLY STOVE USED ( 1 = potbelly stove used all day long, 2 = potbelly stove used most of the day, 3 = potbelly stove only used at night)

CURTANS USED FOR INSLUATION ( 1 = no curtains, 2 = some curtains used, 3 = all windows have curtains)

BAMBOO USED FOR INSULATION ( 1 = no bamboo used, $2=$ some bamboo used, $3=$ bamboo is used in all sleeping rooms)

HOT SHOWERS OFFERED ( 1 = hot showers offered and not charged, 2 = hot showers offered and charged inefficient amount; 20 Rupees, $3=$ hot showers offered and charged appropriate amount; 100 Rupees)

DINING SEPARATE FROM KITCHEN (1 = dining not separate from kitchen, 2 = dining sometimes separate from kitchen, 3 = dining always separate from kitchen)

LOCAL DECOR USED IN LODGE ( 1 = no local decor, 2 = some local decor, 3 = only local decor)

CHARGE FOR HOT WATER ( 1 = no charge for hot water, 2 = sometimes charge for hot water, 3 = always charge for hot water)

One-Year and Five-Year Goal Rankings

$1=$ activity not attempted or not started, group not meeting, kerosene use not monitored, no local guide offered

$2=$ activity in progress/plans are being made, materials are being bought, TMC planning committee meeting

$3=$ project or group has regular meetings, women's group cleaning trails, school has been built, TMC is meeting every $2-3$ months, funds collected as portion of tourism product/service sales for use in conservation or community development. 


\section{APPENDIX D}

\section{Interview Questions and Responses}

*Respondent(s) coding is such that:

1 = Dhunche; 2 = Kyangzin; $3=$ Lama Hotel; $4=$ Langtang Village; $5=$ Sing Gompa; $6=$ Gosainkund Lake; $7=$ Kutumsang; $8=$ Melamchigyang; $9=$ Tarkegyang; $10=$

Shermathang

$\mathrm{L}=$ lodge (direct beneficiary) representative

$U=$ non-lodge/user group (non-direct beneficiary) representative

$\mathrm{T}=$ Tourism Management Committee representative

Satisfaction With the LEP (Table 2-1)

1. What ecotourism projects have worked well in your village?

"The ecotourism projects that have worked well in our village include...

... lodge management."

Respondent(s): 1L, 2L, 5L, 7L, 10L, 1U, $2 \mathrm{U}$

...cooking training."

Respondent(s): 1L, 2L, 7L, 8L, 9L, 10L, 7U

... language training."

Respondent(s): $1 \mathrm{~L}$

... kerosene depot."

Respondent(s): 2L, 3L, 4L, 7L, 8L, 2U, 4U, 7U, 8U

...the ability to have tourists stay longer for nature/wildlife viewing."

Respondent(s): $3 \mathrm{~L}$

... committee formation for tourism management."

Respondents: $3 \mathrm{~L}, 1 \mathrm{U}$

... the creation of the helipad."

Respondent(s): 3L

... the building of the water tank."

Respondent(s): $3 \mathrm{~L}$ 
...trail construction."

Respondent(s): $3 \mathrm{~L}$

...trail clean-up."

Respondent(s): $3 \mathrm{~L}$

.. village garbage management."

Respondent(s): 5L, 6L, 7U, 8L, 9L, 9U, 1U, 2U

...the creation of the cultural museum."

Respondent(s): 10L

... reduced fuelwood use."

Respondent(s): 7L, 8L, 2U, 4U

...empowerment of locals."

Respondent(s): 5L

...increased incomes."

Respondent(s): 10L, 10U

...increased ability to satisfy tourists."

Respondent(s): $7 \mathrm{U}$

...training's for preparing future action plans."

Respondent(s): $1 U$

... building toilets."

Respondent(s): $1 U$

... a study tour."

Respondent(s): $1 \mathrm{U}$

2. Do you feel like you were involved with the LEP as much as you wanted to be?

"Yes, I feel I was involved with the LEP as much as I wanted to be because I took part in almost all the project activities."

Respondent(s): 1L, 1U, 2U, 4L, 4U, 5L, 6L, 7U, 8L, 8U, 9L, 10L, 10U

"I was involved in some of the training's, which was enough for me."

Respondent(s): 2L, 9U 
"I didn't personally participate in the training's but spouse was instead, so I was involved that way."

Respondent(s): 3L, 5L

3. How could you have had your needs met better with the LEP?

"There could be a better selection of committee members so the motivation would be better and we would see more results."

Respondent(s): 1L

"The follow-up programs were lacking, so people didn't continue with the project activities."

Respondent(s): 1U, 2L, 10L

"What the LEP did was mostly beneficial."

Respondent(s): 2U, 3L, 4L

"The LEP would have been more beneficial if it would have been lengthened and provided more skills training's."

Respondent(s): 2L, 4L, 4U, 8L, 8U, 9L

"The LEP training's couldn't include all the people, which would have made for increased benefits."

Respondent(s): 5L, 6L, 9U

"If there was better cooperation with the organizations involved it would have been better for the community and country's welfare."

Respondent(s): $\pi \mathrm{L}$

"Our community would have benefited more if the LEP provided more English language training's."

Respondent(s): $7 \mathrm{U}$

"More projects to benefit cultural heritage and then put the area on an international level would have been beneficial."

Respondent(s): 8U

"More study tours would have been beneficial."

Respondent(s): 10L

4. What is ecotourism? How is it different from tourism?

"Ecotourism emphasizes environmental conservation for tourism development." 
Respondent(s): 1L, 1U, 2L, 2U, 3L, 4L, 4U, 9U

"Regular tourism puts more emphasis on money."

Respondent(s): 1L

"Ecotourism includes research, investigation, and cultural exploration."

Respondent(s): $1 U$

"Ecotourism helps with cultural conservation."

Respondent(s): $2 \mathrm{~L}$

"Ecotourism is conservation and good services which help increase incomes."

Respondent(s): 2L, 4L, 7L, 8U, 9L

"I don't know what ecotourism is."

Respondent(s): 7U, 10U

Social Impacts from Ecotourism (Table 2-2)

5. In what ways has ecotourism improved your life?

"Ecotourism has provided clean surroundings in our area."

Respondent(s): 1L, 3L, 4U, 5L

"Ecotourism has helped with fresh air."

Respondent(s): $1 \mathrm{~L}$

Ecotourism has improved the health of locals."

Respondent(s): 1L

"Locals learned about the necessity of environmental preservation."

Respondent(s): $1 \mathrm{~L}$

"Ecotourism plays a role in developing tourism for better incomes and lifestyles."

Respondent(s): 1L, 2L, 2U, 3L, 4L, 4U, 5L, 6L, 7L, 8L, 8U, 9L, 9U,10L, 10U

"Ecotourism helps with the development of tourism business skills, conservation, and personal empowerment."

Respondent(s): 1U, 2L, 4L, $7 \mathrm{U}$

"Ecotourism has improved our villages capacity building skills."

Respondent(s): $1 \mathrm{U}$ 
"Ecotourism has promoted equity of benefits in villages."

Respondent(s): 10

"Ecotourism has contributed to environmental conservation."

Respondent(s): $2 \mathrm{U}, 4 \mathrm{~L}$

"Ecotourism has contributed to cultural conservation."

Respondent(s): $2 \mathrm{U}, 4 \mathrm{~L}$

"Ecotourism has helped us learn to compete with one another for improved quality of hotel and lodge standards."

Respondent(s): 3L

6. What problems has ecotourism caused in your daily life?

"Ecotourism has caused no problems in our daily life."

Respondent(s): 1L, 2L, 2U, 3L, 4L, 4U, 5L, 6L, 7L, 7U, 8L, 8U, 9L, 9U, 10L, 10U

"Ecotourism has caused cultural dilution."

Respondent(s): $1 \mathrm{U}$

"Locals are paying higher rates for porters because of tourism."

Respondent(s): $1 \mathrm{U}$

"The community has not utilized the skills and lessons from the LEP training's well." Respondent(s): 10L

7. Has ecotour ism helped protect your culture? If yes, how? If no, why?

"Yes, ecotourism has helped with protecting culture by increasing awareness of it's importance."

Respondent(s): 1L, 1U, 2L, 2U, 3L, 4L, 5L, 6L, 8L, 9L, 9U, 10U

"Because of ecotourism, we now perform cultural dances and performances."

Respondent(s): 1L, 1U, 3L, 4L, 4U, 8U

"We now produce handicrafts for tourists."

Respondent(s): $1 \mathrm{~L}$

"Cultural conservation generates income, which helps the community."

Respondent(s): 1L, 2L, 4U 
"The present political situation keeps us from doing what we want for cultural conservation."

Respondent(s): $1 \mathrm{U}$

"Ecotourism helped with the formation of the mothers group which organized cultural performances."

Respondent(s): 4L, 4U

"Ecotourism has helped in promoting fund raising for community projects."

Respondent(s): $4 \mathrm{~L}$

"Ecotourism has had no effects, positive or negative on the culture."

Respondent(s): 7L, $7 \mathrm{U}$

"Ecotourism discourages locals from wearing western clothing."

Respondent(s): 8L

"Ecotourism helped with the establishment of the cultural museum."

Respondent(s): 10L

"It's a pity that locals are not responsible in protecting the culture because they have not been able to follow what they learned about cultural conservation."

Respondent(s): 6L, 10L, 10U

8. Has your culture been negatively effected by ecotourism? How?

"Ecotourism has caused no negative effects on our culture."

Respondent(s): 1L, 2L, 2U, 3L, 4L, 4U, 5L, 6L, 7L, 7U, 8L, 8U, 9L, 9U, 10L, 10U

"The LEP allowed daily allowances during training's, so now locals are spoiled and its difficult to organize workshops at a low cost."

Respondent(s): $1 \mathrm{U}$

9. How does your community plan ecotourism activities?

"Our community has made no plans for ecotourism activities."

Respondent(s): $1 \mathrm{~L}$

"The community prepares yearly plans at a general assembly."

Respondent(s): $1 \mathrm{U}$

"The community plans ecotourism activities at regular meetings."

Respondent(s): 2L, 2U, 3L, 4L, 4U, 5L, 7L, 7U, 8U, 9U 
"Before each tourism season, the community plans a clean-up campaign."

Respondent(s): 5L, 6L

"Meetings are regular, but very little is done with the plans."

Respondent(s): $6 \mathrm{~L}, 10 \mathrm{U}$

"The community plans ecotourism activities according to the funds available." Respondent(s): $8 \mathrm{~L}$

"There use to be meetings when the mother's group was active, but not anymore." Respondent(s): 9L

"Most of the educated people are no longer living in the village, only the old and uneducated are left, so it is difficult to make plans and have results."

Respondent(s): 10L

10. How does your community monitor ecotourism activities?

"Our community has no ecotourism monitoring strategies."

Respondent(s): $1 \mathrm{~L}$

"There are different committees for monitoring the different activities."

Respondent(s): $1 U, 7 \mathrm{~L}$

"The community (leaders) does the monitoring."

Respondent(s): 2U, 3L, 4l, 4U, 5L, 6L, 8L, 9U

"We monitor ecotourism activities at meetings through discussions."

Respondent(s): $2 \mathrm{~L}$

"The Tourism Management Committee does the monitoring of ecotourism activities." Respondent(s): 5L, 7U

11. What would you like your culture to be like in five years?

"Would like the culture to be maintained/protected for the next five years."

Respondent(s): 1L, 1U, 2U, 3L, 4L, 4U, 6L, 7U, 8L, 8U, 9L, 9U, 10L

"Our culture is effected by western culture; the youth are effected and their parents follow."

Respondent(s): $1 \mathrm{~L}$ 
"Old persons who are the source of the old culture are dying off, so the culture is dying off too."

Respondent(s): $1 \mathrm{~L}$

"I would like to see a cultural museum."

Respondent(s): $1 \mathrm{U}$

"I would like a cultural organization to be working to preserve the culture."

Respondent(s): $1 \mathrm{U}$

"I want to preserve the culture for better income."

Respondent(s): $2 \mathrm{~L}, 3 \mathrm{~L}, 4 \mathrm{~L}$

"I want the lodges and hotels to use the traditional foods."

Respondent(s): $1 \mathrm{U}$

"Culture is degrading day-by-day due to community carelessness; would like community to take more responsibility for cultural conservation to happen."

Respondent(s): $3 \mathrm{~L}, 5 \mathrm{~L}, 8 \mathrm{U}$

Environmental Impacts from Ecotourism (Table 2-3)

12. What natural resources are being conserved well in your area and how is this being done?

"The natural resources (NR) in our area are conserved well."

Respondent(s): 1L, 4U, 5L, 10L, 10U

"Forests are conserved well in our area."

Respondent(s): 8L, 8U, 9L, 9U

"Wildlife is conserved well in our area."

Respondent(s): 10L

"Fuelwood is not allowed for cooking which helps with NR conservation."

Respondent(s): $1 \mathrm{U}$

"Most porters are aware of NR conservation due to the eco-porter training's which helps with conservation."

Respondent(s): $1 \mathrm{U}$

"It is difficult to conserve resources due to lodges being built and furniture needing to be made." 
Respondent(s): 2U, 3L

"The army cuts trees and kills wildlife."

Respondent(s): $2 \mathrm{U}, 4 \mathrm{~L}, 7 \mathrm{U}$

"We fine those who cut rhododendron plants and other plants near the walking trail."

Respondent(s): $9 \mathrm{U}$

"The National Park staff kills wildlife."

Respondent(s): $2 \mathrm{~L}, 10 \mathrm{U}$

"Poachers kill wildlife and sell valuable parts for money."

Respondent(s): 5L

"Plantations and done which helps with conservation."

Respondent(s): 3L, $5 \mathrm{~L}$

"Most people use firewood for cooking and build homes."

Respondent(s): $5 \mathrm{~L}$

"There are no trees due to the high elevation, so forest conservation is not an issue here." Respondent(s): $6 \mathrm{~L}$

"Those who know about conservation, do well; those who don't know about conservation continue to cut trees."

Respondent(s): $7 \mathrm{~L}$

13. What are the benefits of protecting the wildlife in your area?

"Wildlife conservation equals increased tourism, which means an increase in earnings."

Respondent(s): 1L, 1U, 2L, 3L, 4L, 4U, 5L, 6L, 7L, 7U, 8L, 8U, 9L, 9U, 10L, 10U

"The red panda and red monkey are endangered animals in our area and get protection." Respondent(s): $1 \mathrm{U}$

"Tourists do research on wildlife, so if it is preserved we can benefit." Respondent(s): $2 \mathrm{U}$

14. What are the benefits of protecting the forests in your area?

"Forest resources are more easily found through protecting them (i.e., fodder, wood for furniture, and firewood)."

Respondent(s): 1L, 1U, 2U, 2L, 4L, 4U, 5L, $\mathrm{L}, 7 \mathrm{U}, 8 \mathrm{~L}, 8 \mathrm{U}, 9 \mathrm{~L}, 9 \mathrm{U}, 10 \mathrm{U}$ 
"With protected forests, more tourists will visit the area which will increase incomes." Respondent(s): 1L, 1U, 3L, 5L, 7L, 7U, 8U, 10L

"Protected forest resources provide fresh air."

Respondent(s): 1L, $5 \mathrm{~L}$

"Protected forest resources prevent landslides and soil erosion."

Respondent(s): $1 \mathrm{U}$

"Protected forest resources provides regular rainfall for farmers."

Respondent(s): $2 \mathrm{U}, 4 \mathrm{~L}$

"Wildlife increase with the shelter provided by a well protected forest."

Respondent(s): 2L, 3L, 8L

"Livestock grasses increase with protected forests."

Respondent(s): $2 \mathrm{~L}$

"Healthy forests provide beautiful surroundings."

Respondent(s): 1L, 3L, 4L, 4U, 10L

15. Do people in your community want to conserve these resources? Why or why not?

"Those who care about resource protection, want to conserve; those who don't care about the resource protection, don't want to conserve (some yes, some no)."

Respondent(s): 1L, 7L, 7U, 10L, 10U

"Most people in our village are aware of the benefits of conservation and are doing plantations in hopes of improving the resources."

Respondent(s): 1U, 3L, 5L, 8L, 8U, 9L, 9U

"Only a few people have initiated conservation projects, but most of the villagers don't care and are busy with their own business."

Respondent(s): $2 \mathrm{U}, 4 \mathrm{U}, 4 \mathrm{~L}, 6 \mathrm{~L}$

"The Japanese supported a plantation, but it failed due to the lack of community support." Respondent(s): $2 \mathrm{U}$

"Some care about conservation and are doing plantations, but the LEP was short so it has been impossible to have good conservation practices."

Respondent(s): $2 \mathrm{~L}$ 
16. How would you like your natural environment to be in five years?

"I would like there to be fresh air and would like it to be a good place to live." Respondent(s): 1L, 3L, 4U, 6L, 7U, 8L, 8U, 9L, 9U, 10L, 10U

"Would like there to be lots of vegetation and to have a dense forest due to good conservation practices."

Respondent(s): 1U, 3L, 5L, 7L, 10L, 10U

"Want there to be lots of plantations to help with forest conservation."

Respondent(s): 1U, 9U

"Would like the use of firewood to be banned."

Respondent(s): $2 \mathrm{~L}$

"Would like there to be more tourists to increase tourist numbers."

Respondent(s): $4 \mathrm{~L}$

"Achieving conservation is a dream I have and would like to achieve this by teaching others."

Respondent(s): $7 \mathrm{U}$

17A. How does your community plan to conserve its natural resources? 17B. What are the current activities?

"Only a few people are doing plantations."

Respondent(s): 1L, 1U, 2U, 4L, 7L, 8L, 8U, 9L, 10L, 10U

"Our community has plans for conservation, but no action has been taken yet." Respondent(s): $2 \mathrm{~L}, 5 \mathrm{~L}$

"Our community makes plans for conservation during our regular meetings." Respondent(s): 3L, 4L, 7L, 7U, 8L

"We focus on plantations, but due to lack of seedlings, it is difficult to continue with these programs."

Respondent(s): $9 U$

"It is understood in our community that if you cut down a tree, you must plant five to six seedlings."

Respondent(s): 3L

"Locals receive 400 Rupees for every 5 seedlings planted." 
Respondent(s): 4L

"Our community has made no efforts towards conservation."

Respondent(s): $6 \mathrm{~L}$

"Our community has awareness programs."

Respondent(s): 8L

Economic Impacts from Ecotourism (Table 2-4)

18. How has ecotourism helped your village economy? Why is this?

"Before the LEP, lodge owners were the only ones who benefited from tourism, now there is more equity within the village."

Respondent(s): 1L, 2U, 4L, 4U, 5L, 7U, 8L, 8U, 9L, 10L, 10U

"Ecotourism has heiped improve the quality of lodge services."

Respondent(s): $1 \mathrm{U}$

"Porters now earn better wages and have better skills."

Respondents: $1 \mathrm{U}$

"We have learned a variety of ways to increase income through ecotourism."

Respondent(s): 2U, 2L, 1U, 2L, 3L, 5L, 6L, 7U, 8U, 9U, 10L

"Ecotourism has promoted cultural traditions."

Respondent(s): 3L

"Ecotourism has only benefited those who took part in the LEP training's and gained the necessary skills to benefit."

Respondent(s): $7 \mathrm{~L}$

19. How does conservation of your environment and culture help you financially or otherwise? How will it help you in the future?

"Conservation of the environment and culture means more tourists will be attracted to the area which means increased incomes."

Respondent(s): 1L, 1U, 2U, 3L, 4L, 4U, 5L, 6L, 7L, 7U, 8L, 9L, 9U, 10L, 10U

"Conservation offers fresh air and a healthy life."

Respondent(s): $1 \mathrm{~L}$ 
"Conservation will bring back a good environment and protect the culture; tourists love these things, so they will come back again and again."

Respondent(s): 2L, 8L, 8U

20. How does conservation of the environment and culture cause problems for you financially or otherwise? And in the future?

"Conservation of the environment and culture have caused no problems financially or otherwise."

Respondent(s): 1L, 2U, 3L, 4L, 4U, 5L, 6L, 7L, 7U, 8L, 8U, 9L, 9U, 10L, 10U

"Conservation of the animals results in crop destruction."

Respondent(s): 1U, 5L

21. How does your community raise funds for community projects? Who contributes?

Who benefits from these funds?

"The United Nations Development Program (UNDP) funded a study program and building toilets."

Respondent(s): $1 \mathrm{~L}$

"The Mother's Group used to collect money, but the funds were misused so that is on longer happening."

Respondent(s): $1 \mathrm{~L}$

"Lodge owners learned better management skills from the study tour."

Respondent(s): 1L

“Our own tourism organization, INGO's, and government organizations help with community projects."

Respondent(s): $1 \mathrm{~L}$

"When the TMC was working, it used to raise funds from lodge owners for clean-up and garbage management projects."

Respondent(s): 2L, 2U, 5L, 8L

"We collect 14 Rupees bed tax for each tourist and it goes to community projects." Respondent(s): 3L

"Those who don't help physically in projects, contribute money." Respondent(s): 4L, 9U

"Cultural shows help with raising funds." 
Respondent(s): $4 \mathrm{U}$

"We get funds from DDC (District Development Committee) not from the community." Respondent(s): $5 \mathrm{~L}$

"The lodges raised funds to collect revenue for clean-up at Gosainkund Lake." Respondent(s): 6L, $7 \mathrm{~L}$

"Our community hasn't received any outside funds, instead we collect a levy from the TMC members for community projects."

Respondent(s): 7U, 9L, 10L, 10U

"Our community does projects on our own."

Respondent(s): 8U

22. Are vegetables, poultry, and handicrafts produced and sold in your village? Who produces them? Who buys them?

"Most of the vegetables are grown locally and sold to lodges and tourists."

Respondent(s): 1L, 1U, 2U, 2L, 4L, 5L, 7L

"Handicrafts are produced locally and sold to lodges and tourists."

Respondent(s): 1L, 1U, 2U, 5L, 6L, 7U

"Poultry is produced mostly from outside villages because our community is Buddhist." Respondent(s): 1L, 2L, 2U, 3L, 4U, 5L, 6L, 7L, 9L, 10L

"Only some vegetables are grown locally, mostly they are brought in from outside villages."

Respondent(s): 3L,6L, 7U, 8L, 8U, 9L, 9U

"Only some handicrafts are produced locally, mostly they are brought in from outside villages."

Respondent(s): 3L, 4L, 4U, 5L, 7L, 8L, 8U, 9U

23. How do locals who do not own a lodge make money from tourism? Do they benefit in any other way from ecotourism?

"Locals who do not own a lodge make money by growing vegetables."

Respondent(s): 1L, 1U, 4L, 4U, 7L, 7U, 8L, 8U, 9L, 9U, 10L, 10U

"Locals who do not own a lodge make money by herding and producing livestock." Respondent(s): 4L, 4U, 10L, 10U 
"Locals produce handicrafts to earn income from tourists."

Respondent(s): 1L, 1U, 7L, 7U, 9L, 9U

"All homes in our village are a lodge."

Respondent(s): 3L, 5L, 6L

"Locals who are not directly involved in ecotourism sell milk and egg products."

Respondent(s): $1 \mathrm{~L}$

"Some locals work as porters and guides."

Respondent(s): 1U, 7U, 8L, 8U, 9L, 9U

"Locals sometimes make money through donations from tourists."

Respondent(s): $8 \mathrm{~L}$

"Offering campsites is a way locals without a lodge make money from tourism." Respondent(s): $8 \mathrm{U}, 10 \mathrm{~L}$

"Renting horses is a way locals without a lodge make money from tourists." Respondent(s): $8 \mathrm{U}$

24. How would you like ecotourism to benefit you financially in the next five years?

"With conservation, tourist numbers will increase and incomes will then also increase." Respondent(s): 1L, 1U, 2U, 3L, 4L, 4U, 5L, 6L, 7L, 7U, 8L, 8U, 9L, 9U, 10L, 10U

"With plantations I hope that the forests will improve."

Respondent(s): $2 \mathrm{~L}$

"Would like to try to manage garbage and keep the local surroundings clean." Respondent(s): $2 \mathrm{~L}$

TMC Success (Table 2-5)

1. What is going well with the TMC?

"Items going well with the TMC...

... construction of the dump site and garbage management."

Respondent(s): 1T, 3T, 4T, 5T

... self employment opportunities." 
Respondents: 1T

... kerosene depot."

Respondent(s): $3 \mathrm{~T}$

... water tank building."

Respondent(s): $3 \mathrm{~T}$

...trail maintenance."

Respondent(s): $5 \mathrm{~T}$

... fixed menu pricing."

Respondent(s): $5 \mathrm{~T}$

...coordination and management of lodges."

Respondent(s): 7T, 8T

... quality of services provided."

Respondent(s): 7T, 8T

...regulating tourism business."

Respondent(s): 7T, 8T

...good participation of committee members and kind cooperation."

Respondent(s): 9T, 10T

2. What needs to be improved with the TMC?

"Improvements needed with the TMC...

...training opportunities for members."

Respondent(s): $1 \mathrm{~T}$

...capacity building."

Respondent(s): $1 \mathrm{~T}$

...all members should obey rules."

Respondent(s): $3 \mathrm{~T}$

... need to development mutual understanding and cooperation."

Respondent(s): $5 \mathrm{~T}$

...needs lots of improvement." 
Respondent(s): 10T

"The TMC needs no improvements."

Respondent(s): $7 \mathrm{~T}$

3. How do other villagers feel about the TMC activities? What are some examples?

"Other villagers appreciate and have a positive attitude towards the TMC activities and have."

Respondent(s): 1T, 5T, 7T, 8T, 9T

"The villagers have little faith that the TMC will produce the planned home-stay program."

Respondent(s): 1T

"The villagers say the surrounding areas are clean due to the TMC."

Respondent(s): $3 \mathrm{~T}$

"The villagers who are educated appreciate the TMC activities, those who are not educated say the projects are worthless."

Respondent(s): 4T

"The LNP appreciates the TMC activities."

Respondent(s): $5 \mathrm{~T}$

"The villagers feel the TMC hasn't done anything, which is true."

Respondent(s): $10 \mathrm{~T}$

4. What activities is the Tourism Management Committee (TMC) involved in at this time?

"The activities the TMC is presently involved with are the construction of a garbage pit with money from the DDC."

Respondent(s): $1 \mathrm{~T}$

"The TMC is planning the development of a home-stay program for the lower village of Dhunche."

Respondent(s): $1 \mathrm{~T}$

"The TMC is presently inactive."

Respondent(s): 3T, 4T, 5T,10T 
"The TMC is distributing newly printed menus and renewing memberships of the lodge owners."

Respondent(s): $7 \mathrm{~T}$

"The TMC is performing clean-up activities."

Respondent(s): $8 \mathrm{~T}, 9 \mathrm{~T}$

"The TMC is imposing penalties for lodge owners who commit misdemeanors."

Respondent(s): $8 \mathrm{~T}$

"The TMC is collecting 100 Rupees from each village household to form a trust fund for development activities."

Respondent(s): $9 \mathrm{~T}$

5. What activities has the TMC done in the past? What worked well and why?

"The TMC published brochures to raise community awareness on conservation issues." Respondent(s): $1 \mathrm{~T}$

"The TMC maintained and constructed trails."

Respondent(s): 1T, 3T, 5T, 8T

"The TMC formed a survey team."

Respondent(s): $1 \mathrm{~T}$

"The TMC organized eco-porter training's."

Respondent(s): $1 \mathrm{~T}$

"The TMC constructed a garbage pit."

Respondent(s): $4 \mathrm{~T}$

"The TMC collected a bed tax for community projects (sign board, built water tank, built helipad)."

Respondent(s): 3T, 4T, 5T

"The TMC maintained clean-up of the surroundings."

Respondent(s): 4T, 8T, 10T

"The TMC organized plantations."

Respondent(s): $5 \mathrm{~T}$

"The TMC organized menus with fixed pricing."

Respondent(s): $7 \mathrm{~T}$ 
"The TMC was fining lodges that disturbed tourists."

Respondent(s): 8T, 7T

"The TMC was not active."

Respondent(s): $10 \mathrm{~T}$

6. What are the goals for the TMC for the next one and five years?

"The TMC goals are...

... to develop a home-stay program."

Respondent(s): $1 \mathrm{~T}$

... to develop new trekking trails."

Respondent(s): $1 \mathrm{~T}$

... to make the village garbage free."

Respondents: $1 \mathrm{~T}$

... to reduce the use of forest resources."

Respondent(s): $3 \mathrm{~T}$

... to bring a communications facility for tourists (during times of emergency)."

Respondent(s): $3 \mathrm{~T}$

...to reform the TMC and make stronger."

Respondent(s): $4 \mathrm{~T}$

... to organize skills enriching training's."

Respondents: $7 \mathrm{~T}$

...to collaborate with the NGO's and NGO's."

Respondent(s): $7 \mathrm{~T}$

... to create a separate office for the TMC."

Respondent(s): $7 \mathrm{~T}$

"There are no goals for the TMC."

Respondent(s): 9T, 10T

7. What are the action plans for these goals 
"The action plans for these goals are...

... to collaborate with NGO's."

Respondent(s): 1T

... to work on community facilities."

Respondent(s): $3 \mathrm{~T}$

... to bring continuity to the kerosene depot."

Respondent(s): $3 \mathrm{~T}$

... to build viewpoints."

Respondent(s): $3 \mathrm{~T}$

...to stop beckoning the tourists to stay a particular lodge."

Respondent(s): $3 \mathrm{~T}$

... we will have a meeting to discuss reforming the committee."

Respondent(s): 4T, 5T

...to raise funds from tourists and other organizations."

Respondent(s): $7 \mathrm{~T}$

...to force lodge and hotel owners to build toilets that don't already have one."

Respondent(s): $8 \mathrm{~T}$

...to make good regulations that will promote better ecotourism practices."

Respondent(s): $8 \mathrm{~T}$

...to maintain good services."

Respondent(s): $8 \mathrm{~T}$

... to prepare signboards for tourists."

Respondent(s): $9 \mathrm{~T}$

"Since there are goals, there are no action plans for the TMC."

Respondent(s): $10 \mathrm{~T}$

8. How many people participate in the TMC meetings?

"Most of the TMC participate in the meetings."

Respondent(s): 1T, 3T, 7T, 8T, 9T 
"The TMC sometimes includes people outside of the committee."

Respondent(s): $1 \mathrm{~T}$

"In the past, most people didn't participate, because their priority was making money." Respondent(s): 4T

"When the committee was active, most of the members participated, and if they didn't, they would pay a fine."

Respondent(s): 5T, 10T

9. Why do some members not participate?

"Some members don't participate because they meetings are too far for them to walk." Respondent(s): 1T, 3T, 9T

"Members who don't participate pay a fine."

Respondent(s): 3T, 7T, 8T

"Some members don't participate because they give priority to their business and own personal work,"

Respondent(s): 4T, 5T, 10T

"Some members don't participate because they are careless towards the committee." Respondent(s): $7 \mathrm{~T}$

"Participants are never absent from the TMC meetings."

Respondent(s): 8T

10. How does the TMC make decisions?

"The TMC makes decisions by letting all the members express their opinions and through discussions."

Respondent(s): 1T, 3T, 4T, 5T, 7T, 8T

"The TMC makes decision through majority vote."

Respondent(s): 1T, 3T, 4T, 5T, 7T, 8T, 9T

"There have been no concrete decisions made."

Respondent(s): 10T

11. How do you keep records of tourism activities?

"The TMC keeps records of tourism activities through records in a minutes book." 
Respondent(s): 1T, 3T, 4T, 5T, 7T, 8T, 9T

"We keep TMC records on soft copy on the computer."

Respondent(s): $1 \mathrm{~T}$

"The TMC submits reports to the LNP."

Respondent(s): $7 \mathrm{~T}$

"There are no records to be kept."

Respondent(s): 10T

12. How do you know if projects are successful or not?

"If a project is completed, than it is considered successful."

Respondent(s): $1 \mathrm{~T}$

"We use the opinions of visitors and other beneficiaries to decide if a project was successful or not."

Respondent(s): $3 \mathrm{~T}$

"We have no measurements of success."

Respondent(s): $4 \mathrm{~T}$

"We determine success according to the impacts."

Respondent(s): 5T, 7T, $9 \mathrm{~T}$

"If menu rates are consistent and tourists are not hassled than we have ecotourism success."

Respondent(s): $8 \mathrm{~T}$

"There is no monitoring of ecotourism projects practiced."

Respondent(s): $10 \mathrm{~T}$ 


\section{APPENDIX E}

\section{Responses from CBE Facilitators}

\section{RESPONDENT \#1:}

Association Talamanquena of Ecotourism and Conservation

Costa Rica

"We don't really have a formal monitoring system... when referring to CBE, I guess our main participation in $\mathrm{CBE}$ is with the local and indigenous tour guides. My observation of the success working with them consists of asking them if they are happy with working with the ATEC (the answer is yes). Also, ask them if they have suggestions for improvement (the answer is no, at this time), other than money. What is working? The work we do together seems to be working, everyone seems happy with ATEC, guides, tourists. You ask why we don't monitor... its is because we have not had time."

\section{RESPONDENT \#2:}

Responsible Ecological Social Tours Project

Thailand

"We have no proper monitoring at the moment. We have done it in a different way during the working process."

\section{RESPONDENT \#3:}

Community Ecotourism for Maya Communities at Lake Mirmar, Chiapas

Mexico

"We keep record of our visitors by country, sex, age, duration of the visit, and how they new about us. I can say $55 \%$ is European, $40 \%$ American-Canadian, $5 \%$ Mexicans. Approximately $60 \%$ are women and $40 \%$ are men between the ages of 22 and 35 . Usually they come for a three day visit."

\section{RESPONDENT \#4:}

Nanda Devi Biosphere Reserve Tourism Project

India

"I wish to inform you that the CBE process in the Nanda Devi Biosphere Reserve is in infancy stage. The local communities are struggling for the restoration of their traditional rights and equity in the upcoming tourism business in their region. We want to include monitoring in the process and our idea is to make it an integral part of the communitybased institutional mechanism we are trying to evolve for regulating and promoting tourism in the region.

The area is rural and inhabited by Bhotia tribal communities. The major stakeholders are the unemployed youth of the area who are presently unskilled and serve as porters only. So we are trying to organize a training program for a few selected youth. 
We are just experimenting. Our main concern is equity because only by institutionalizing equity we can ensure peace in the region."

\section{RESPONDENT \#5:}

\section{Community of San Nicolas Totolapan}

Mexico

"No monitoring is taking place in Mexico. We have on many occasions tried to install a monitoring program in some CBE projectss, but no one seems interested in committing the funds for the project. As for why no one seems to care, I'd say it's because our country seems to thrive on uncontrolled experimentation. There is a lot of money out there if you want to develop a CBE project, but none for research on the consequences for doing so... I can't figure this out. We visit the communities in which we have worked before and observe what has worked and what hasn't worked, but without protocol, just pure observation and intuition."

\section{RESPONDENT \#6:}

Sabah Project

Malaysia

"We have a list of indicators being observed for changes. Most often every time we interact but on ad hoc basis, more formally on quarterly reporting basis. The monitoring is done by both myself (project manager) and the community members."

\section{RESPONDENT \#7;}

\section{Lake Titicaca}

Peru

"Taquile Island tourism is not a "project" per se but an economic development strategy that the community designed with limited outside input over 30 years ago. There are no "managers" or ongoing, formal monitoring and evaluation. Whatever is done is through the community themselves. My general sense is that much like their planning, monitoring is done ad hoc and short-term."

\section{RESPONDENT \#8:}

Dadia Project

Greece

"We are not really doing any monitoring in any official way in our projects. We do have a method of visitor management and monitoring impacts of tourism on the ecosystem in the Dadia Project. We do not monitor, though, all the aspects of ecotourism because the Dadia area is now in the hands of the local communities."

\section{RESPONDENT \#9:}

Programme for Belize

Belize 
"We do not at this particular time conduct monitoring within the communities we may work with. We have begun a process through the Meso American Ecotourism Allilance of which Program for Belize is present to implement Impact Mitigation and Monitoring Program (IMMP) to collect and assess data on the Mea touts that are carried on the Rio Bravo. We will collect visitor data, satisfaction levels, and we have also established the baseline impact data including biodata on the areas that will be used. We have not monitored the impacts (economic or social) that the groups have had on the community as of yet, but we are looking at some options and proposals that can assist us with this."

\section{RESPONDENT \#10:}

Carpathian Large Carnivore Project

Romania

"We do both economic monitoring and monitoring of the number of visitors"

\section{RESPONDENT \#11:}

\section{PanParks}

Poland

"We only have one pilot yet in Buialowieza National Park. The local people themselves do the monitoring, plus our coordinator is having meetings with the local partners three times a year. The monitoring methods that are not working include, remote control (you need a person who runs the project on-site), don't expect too much at the beginning, webmarketing alone is not enough. You need a coordinator who speaks the local language. If there is an ethnic minority group, trust must be build among them too."

\section{RESPONDENT \#12:}

\section{Lake Titicaca Tourism Association}

Conservation International, Peru

"I can say from experience that the answers you seek depend very much on what you are seeking to monitor and how key it is to the survival of the project. The vast majority of ecotourism initiatives are under-funded and have funds for too short a time span, one just tries to do the best one can with the resources you have, given the choice of training people in hygienic food preparation and how to do baseline surveys on the tends to choose the former. In the ten years I have been involved in ecotourism and conservation, I have yet to see a very comprehensive monitoring and evaluation program that has been able to sustain itself beyond the old fashioned business monitoring and evaluation tools of balance sheets and profit and loss accounts."

\section{RESPONDENT \#13}

Namibia Community Based Tourism Association (NACOBTA) Namibia, Africa

1) NACOBTA has Performance Indicator Data System (PID) where we try to collect data to monitor and evaluate the projects. Indicators collected include: 
*Income and expenses (divided into subgroups like entry fees, sales, and loans and operating costs, camping salaries, community benefit, cleaning material, investments, payments, etc.)

* Number of employed: female and male, part and full-time.

*Training given: number of male and female that have received training from NACOBTA.

*What marketing activities the project takes part in.

*The status of record keeping.

*Level of community based enterprises integrated into tourism, e.g.: no. of tour operators using the enterprise, private sector investment, bookings through NACOBTA booking office.

2) The data is to be collected on a monthly basis, because of distances and lack of staff at NACOBTA. This is unfortunately not done regularly.

3) The data is to be collected by NACOBTA business advisors, usually when they visit the project for a workshop. For some of the far away projects we are getting help collecting data by field based NGO's in specific areas. Our aim for the future is that the enterprises will send us the data by mail, fax, or phone on a monthly basis.

4) The data is being collected and analyzed every third month and presented in quarterly reports to donors. But still there is a lot of work to be done to be able to collect correct data on a regular basis from our enterprises. The main constraints for this is poor status or record keeping at the enterprise level, and as mentioned before, lack of time for NACOBTA staff to travel to the enterprises to do this work.

It is very important to focus on WHY monitoring is done and HOW the results are used. The lack of focus and understanding of these two things in the past are the main reasons why NACOBTA's PID system is not working satisfactorily. Collecting data takes time and effort for both enterprises and organization staff, and if there is no clear goal with the collection it will probably not work. It is important to focus on how the data will be analyzed and presented, and how it may help the enterprise in its development in a practical way (not an easy task!). If it is just to be presented in donor reports, why should the enterprise take the effort to do it?

There are other constraints to consider: data is boring, figures look difficult (remember the low level of education at the countryside), and forms must be user-friendly. Data collection and monitoring demand a transparent economic system, something that may not be a priority for the management/staff at the enterprise. If they find out misconduct will be discovered, they may be reluctant to leave correct data. Data collection (like all other projects) must be decided upon "bottom-up" to work, not "top-down". The enterprises must feel they own the monitoring process, that they are helped by its outcomes to do the work for us!" 
RESPONDENT \#14

Uganda community Tourism Association (UCOTA)

Uganda, Africa

"Monitoring is always a difficult activity... how to do it best is always the remaining question. I am therefore delighted to hear that you are doing research. UCOTA has not been very active in a formal way with monitoring due to lack of funds. Recently, however, we started with the collection of baseline information, the base of monitoring.

We like to monitor the following:

1) Quality of services and craft products (not by form, but through field visits and feedback from tour operators/customers).

2) Contribution to community development projects (how livelihoods are improved).

3) Number of employees directly benefiting.

4) Gender division of employees and what position they hold.

5) Income generated by the activity.

Monitoring takes place yearly, members will fill in the form when they come for the general annual meeting. There are separate monitoring plans for trainings that take place. The method still has to be developed. Most of the time this is done by who funds a particular project activity and will also fund the monitoring part of it. Once again, the main challenge is the lack of human and financial resources to carry out the monitoring and therefore experience in this field is still low."

\section{RESPONDENT \#15}

Salpa Arun Conservation Project

Nepal

1) "During this time, the staff has collected information about all the visitor facilities located along this route from Pangom to the Arun Valley. The previous report was used for location and lodge operators and interviewing the proprietor, if he or she was available and willing to be interviewed. Information about campsites, lodges, and teahouses was collected according to a questionnaire that asked about location data, condition of the facilities, services provided, means to alternative fuel to reduce the firewood use, and other environmental impacts such as refuse disposal, methods of refuse disposal and waste management system. Methodology for this project was very straightforward and this has been design to be or replicated by other groups in the future.

2) The staff monitored lodges, teashops, and campsites along the trail from Pangom, Shibuje, Nazing, Khiraule, Bung, Gudel, Sonam, Guranse, Phedi, Dovane, and Kartikighat. Basic services including small shops, food and lodging were available. Tourism related facilities, such as lodges and campsites, practiced conservation activities 
that had been implemented by the Department of National parks and The Mountain Institute, such as trail signposts, signboards that listed the minimum impact practices for trekkers. Similarly, lodge owners recalled having received training from MBNP and its conservation partners and also built pit toilets and cooking shelters.

3) For the last two years, there has been a decline in tourism in Nepal and also this particular route due to:

a. Down fall of economy

b. Unstable government

c. Fear of flying

d. Weak promotional activities

e. Terrorism and Maoist Insurgency

f. Lack of Security

g. Lack of tourism potential area

h. Global scenario like attack, Afghan War, attack on Indian Parliament

i. Havoc created by Indian Media

j. Negative feeling about Nepal

k. High tariff rate compared to neighboring countries

These reasons, and above all, the terrorism and Maoist Insurgency, has created problems, and so monitoring has not happened since 2001. The original plan was to monitor each year during the month of August and September, as this is a good time for all farmers or the proprietors along the route.

4) The Mountain Institute's second phase program, named The Community Partnership Program (CPP), has an agreement with the Hill Development, Conservation Group (HDCG), and local NGO from Bung VDC of Solu Khumbu. DGCG/Nepal staff spent two weeks in this particular route monitoring, i.e. Salpa-Arun conservation Area.

5) Monitoring the campsites, lodge operators, teahouses, and other conservation activities, trail improvement, signposts, publicity, maps, and visitor flow were all possible and easy to observe and monitor for the condition of this route. These were working. What is not working while monitoring is the income derived from the visitors, as they will not share this information with the staff due to the Maoist problem. You can't tell how much income you make and also local people have no desire to improve the lodge or campsites conditions.

6) Finances are a major problem for conducting monitoring in this area, despite the terrorism and Maoist Insurgency. The staff that does the monitoring does not feel safe walking or conducting the programs, but could be done if there were some improvements such as:

a. Maintaining security

b. Reducing the tariff rate of tourism sectors 
c. Increasing flight schedules in various countries and sectors

d. Showing good hospitality and behavior

e. Stopping Nepal Bands Strike and political disturbances are reduced. 